\title{
Examining the Link Between Sexually Explicit Media use and Sexual Risk Behavior Among Adolescents and Young Adults
}

A. Jamesa Wagwau

Follow this and additional works at: https://researchrepository.wvu.edu/etd

\section{Recommended Citation}

Wagwau, A. Jamesa, "Examining the Link Between Sexually Explicit Media use and Sexual Risk Behavior Among Adolescents and Young Adults" (2016). Graduate Theses, Dissertations, and Problem Reports. 6884.

https://researchrepository.wvu.edu/etd/6884

This Thesis is protected by copyright and/or related rights. It has been brought to you by the The Research Repository @ WVU with permission from the rights-holder(s). You are free to use this Thesis in any way that is permitted by the copyright and related rights legislation that applies to your use. For other uses you must obtain permission from the rights-holder(s) directly, unless additional rights are indicated by a Creative Commons license in the record and/ or on the work itself. This Thesis has been accepted for inclusion in WVU Graduate Theses, Dissertations, and Problem Reports collection by an authorized administrator of The Research Repository @ WVU. For more information, please contact researchrepository@mail.wvu.edu. 
Examining the Link Between Sexually Explicit Media use and Sexual Risk Behavior Among Adolescents and Young Adults
A. Jamesa Wagwau

Thesis submitted to the

College of Education and Human Services

at West Virginia University

in partial fulfillment of the requirements for the degree of

\author{
Master of Arts \\ in \\ Educational Psychology \\ with an emphasis in Child Development and Family Studies
}

Kristin L. Moilanen, Ph. D., Chair

Carol Markstrom, Ph.D.

Leslie Cottrell, Ph.D.

Department of Learning Sciences and Human Development

\author{
Morgantown, West Virginia
}

2016

() 2016 A. Jamesa Wagwau 


\section{Abstract \\ EXAMINING THE LINK BETWEEN SEXUALLY EXPLICIT MEDIA USE AND SEXUAL RISK BEHAVIOR AMONG ADOLESCENTS AND YOUNG ADULTS}

\section{A. Jamesa Wagwau}

The current study examined the link between sexually explicit media use and the different forms of sexual risk-taking among emerging adults. The study focused on emerging adults aged $18-25$ years. This is a critical stage for sexual risk-taking which has not been adequately investigated by prior studies. Using online data collected from 146 American based young adults $(45.1 \%$ female; 74.6\% European American, 9.7\% Asian /Asian American, 6.7\% Black/African American, $0.7 \%$ Native American and 8.2\% Multiethnic, mean age $=22.89$ years), sexually explicit media use was analyzed in connection with sexual risk-taking variables (i.e., multiple sexual partners, condom use and high risk sexual behavior). Bivariate analyses revealed no significant correlations between sexually explicit media use and the three different forms of sexual risk-taking. Consistent with the study's second hypothesis, males reported higher levels of sexually explicit media use and higher levels of high risk sexual behavior than the females. In addition, regression analysis revealed that sexually explicit media use was significantly associated with a person's number of sexual partners as well as their engagement in high risk sexual behavior. The findings of the current study are a reflection of inconsistent findings in the existing literature and evidence that the link between sexually explicit media use and sexual risktaking might not be as direct as assumed. 


\section{PORN CONSUMPTION AND SEXUAL RISK-TAKING}

\section{Dedication}

For my children, Samuel Jamesa Wagwau, Salome Achieng Wagwau and David Onyango

Wagwau whose curiosity and insatiable thirst for exploration ignited my initial interest in the study of child development 


\section{Table of Contents}

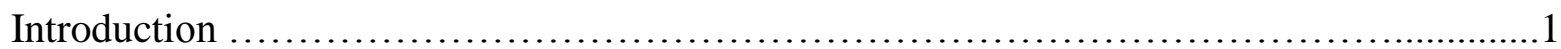

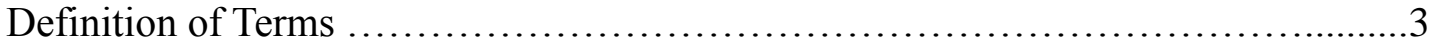

Statement of the Problem …......................................................

Literature Review ....................................................................

Theoretical Framework .......................................................

Sexual Media and Sexual Risk Behavior.........................................

Multiple Sexual Partners ................................................... 10

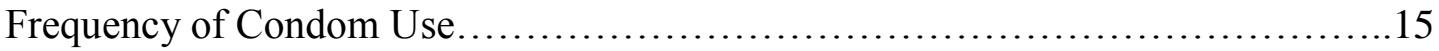

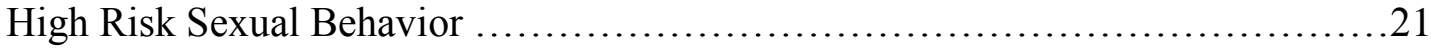

Sexual Attitudes and Pre-Coital Behavior......................................23

Conclusions and Literature Gaps............................................ 30

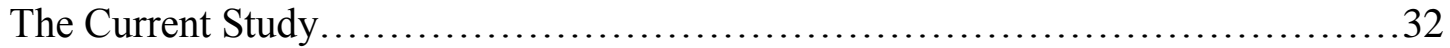

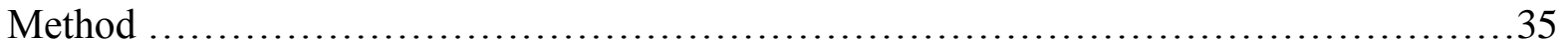

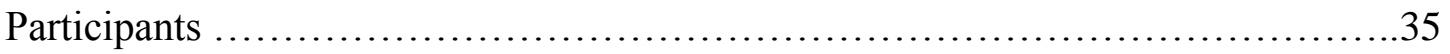

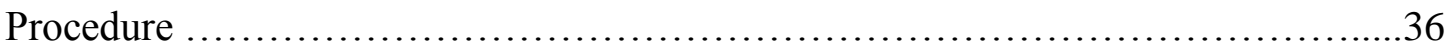

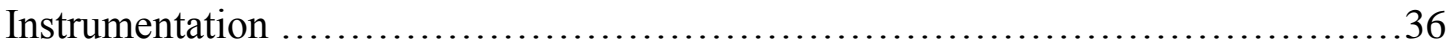

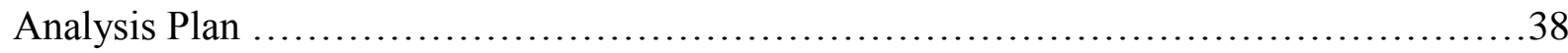

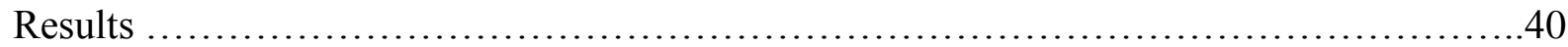




\section{PORN CONSUMPTION AND SEXUAL RISK-TAKING}

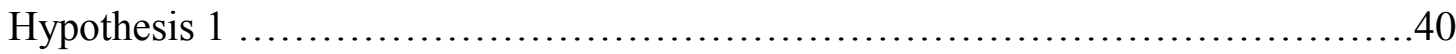

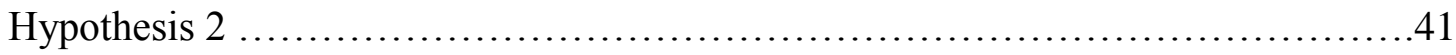

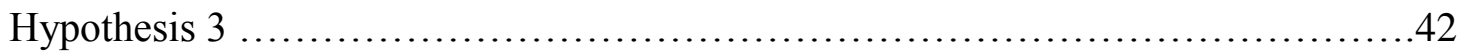

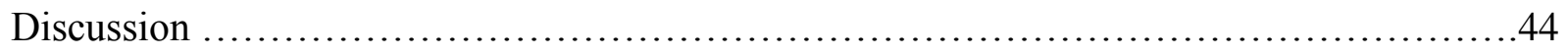

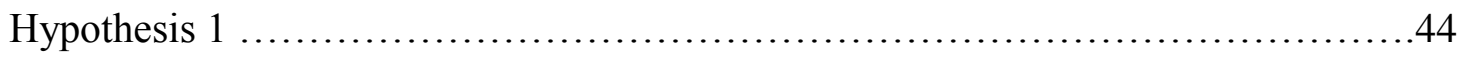

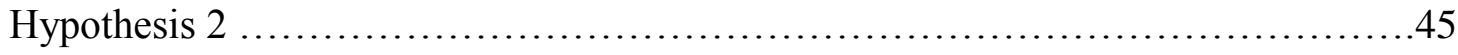

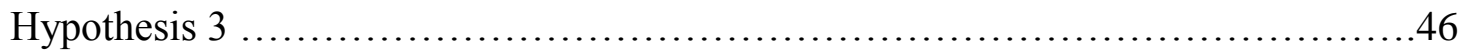

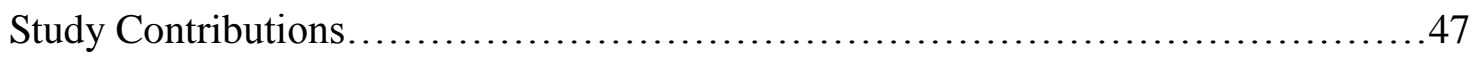

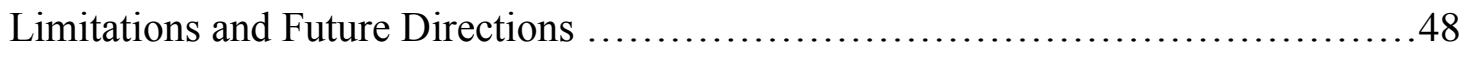

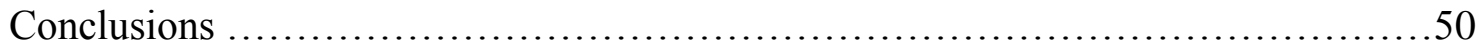

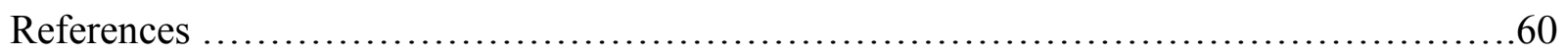




\section{PORN CONSUMPTION AND SEXUAL RISK-TAKING}

\section{List of Tables}

Table 1 - Descriptive Statistics ...............................................66

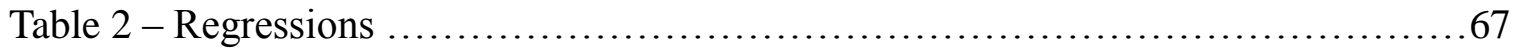




\section{PORN CONSUMPTION AND SEXUAL RISK-TAKING}

\section{List of Appendices}

Appendix A - Demographic Questionnaire

Appendix B - Frequency of Intentional Exposure to Sexually Explicit Media

Appendix C - Number of Sexual Partners

.58

Appendix D - High Risk Sexual Behavior 


\section{PORN CONSUMPTION AND SEXUAL RISK-TAKING}

\section{Chapter I}

\section{Introduction}

The current technological advancement in the United States has increased access to both computers and the Internet. According to the American Community Survey Report (ACSR, 2013), approximately $92 \%$ of the youth within the age group of 15-34 years in the U.S. own personal computers and $78 \%$ of this group also uses the Internet on their computers. National surveys also show that computers are mainly owned by households with comparatively younger age group (ACSR, 2013). For instance only $65 \%$ of homes with people aged 65 years and above owned computers as compared to $92 \%$ of homes with people aged 15-34 years (ACSR, 2013). This survey shows that a large percentage of American youth have Internet access with an approximated $95 \%$ of them accessing the Internet regularly. Around $74 \%$ of the youth access the Internet using their mobile devices (ACSR, 2013). Studies also rank video watching as the leading online activity for American teens with $82 \%$ of teenagers reporting regular visits online to watch videos (ACSR, 2013).

Although this technological advancement especially in regard to information access is a positive development, increased Internet access also is increasingly raising fears of potential misuse by curious developing teenagers. For example, teenagers are at risk of seeking out pornographic content online (Ybarra \& Mitchell, 2005). This risk of misuse has motivated numerous studies in which researchers explore the impact that unrestricted access to online information might have on the development of teenagers (Morgan, 2011). Researchers are increasingly becoming interested in especially the impact that online pornography might have on sexual behavior of teenagers. Compounding the risk of unrestricted Internet access is the potential link between pornography consumption and sexual risk-taking. The need for deeper 


\section{PORN CONSUMPTION AND SEXUAL RISK-TAKING}

research in this area is more urgent right now than ever before.

The consequences that come with sexual risk behavior are becoming a source of concern. According to Centers for Disease Control and Prevention (CDC, 2015), there are more than 1.2 million people who are living with HIV in the U.S., $15 \%$ of which are not aware of their HIV status. Records also show that about 50,000 people are infected with HIV every year (CDC, 2015). In spite of the HIV spread, the use of condoms and other contraceptives among the American youth is still low. The 2013 National Youth Risk Behavior Survey on the percentage of high school students that used birth control pills were as follows: $8.2 \%$ Blacks, 9.0\% Hispanics, and $25.9 \%$ Whites. The percentage recorded for condom use was slightly higher with Blacks taking the highest slot of $64.7 \%$ followed by Hispanics at $58.3 \%$ and the Whites $57.1 \%$ (Frieden et al., 2014). This low contraceptive use leads to high numbers of teenage pregnancies and sexually transmitted infections. Currently, the U.S. leads other industrialized countries like Great Britain, Canada, France and Sweden in teenage births. According to a 2001 report $22 \%$ of American women had given birth before they turned 20 years as compared to Great Britain which reported $15 \%$, Canada which reported $11 \%$ or France in which only six percent reported having had babies before they turned 20 (Darroch, Singh, \& Frost, 2001). As compared to teens in Canada, the American female teenager is more than twice likely to get a baby and nearly ten times as likely to have a baby as a teenager in Switzerland (Kearney \& Levine, 2012).

In addition, Centers for Disease Control and Prevention (CDC, 2016) reports that high teenage pregnancies, around $50 \%$ of the 20 million new cases of sexually transmitted infections recorded annually in the U.S. are aged 15-24 years (CDC, 2016). The CDC (2016) report also revealed that out of ten sexually active teenaged girls in the U.S., four had suffered from a lifethreatening sexually transmitted infection (CDC, 2016). Specifically, Chlamydia and gonorrhea 


\section{PORN CONSUMPTION AND SEXUAL RISK-TAKING}

infections were highest among females within the age bracket of 15-19 years (Cavazos-Rehg et al., 2009). Although only a quarter of the U.S. population is aged 15-24, studies show that 50\% of new STD infections are reported within this age bracket (Chesson et al., 2004). These infections come with immense medical costs. According to the Chesson et al. (2004) study, the direct cost implication attributed to STDs within the age bracket of 15-24 years was estimated at six and a half billion dollars in the year 2000. The high STD infection rate problem is further exacerbated by mean age of first sexual intercourse. Around $30 \%$ of females and $34 \%$ of males in the U.S. have had sex by the time they turn 16 (Cavazos-Rehg et al., 2009). The mean age of first sexual intercourse also vary according to ethnicity. For example, African Americans are likely to have their first sexual intercourse earlier than Hispanic and Caucasian teenagers (Cavazos-Rehg et al., 2009). Overall, approximately $70 \%$ of teenaged population in the U.S. report having had sex by time they turn 18 with an estimated seven percent reporting having had their first sexual intercourse before they turned 13 (Cavazos-Rehg et al., 2009).

These staggering statistics of HIV infections, sexually transmitted infections coupled with low condom use among American teens indicate that a great deal still needs to be done in regard to sexual risk-taking.. In spite of the challenges that Americans teens face in this regard, very few studies done so far have focused on older teens. The current study addresses this methodological gap in the existing literature by focusing on $18-25$ years. In addition to this, the current study also measures the frequency of exposure to sexually explicit media on a threemonth time frame as opposed to twelve-month time frame commonly used in prior studies.

Definition of terms. The current study examined the relationship between sexually explicit media use and sexual risk behavior of adolescents and emerging adults. It was hypothesized that there would be a positive correlation between sexually explicit media use and 


\section{PORN CONSUMPTION AND SEXUAL RISK-TAKING}

sexual risk-taking. Respondents highly exposed to sexually explicit media would show higher sexual risk-taking than those who are less exposed. The second hypothesis was that males would show higher levels of sexually explicit media use than the females. The third hypothesis was that males who are exposed to sexually explicit media would show higher levels of sexual risk-taking than the females who are exposed to sexually explicit media.

For the purposes of this study, the phrase "sexually explicit media" (SEM) refers to any material intended to arouse erotic feelings or thoughts in a person (Rosser et al., 2012). The phrase "sexually explicit media" has also been used synonymously with the word pornography (Brown \& L'Engle, 2009). The current study focused on the frequency of intentional exposure to SEM. For the purpose of the current study, frequency of intentional exposure to SEM refers to the number of times or how regularly a person seeks out pornographic content.

Although the current study examined frequency of condom use, multiple sexual partners and high risk sexual behavior as its key outcome variables, the literature on other variables that have a link with sexual risk-taking were also reviewed below (e.g., studies show that sexual attitudes prepare the ground for potential sexual risk behavior; Braun-Courville \& Rojas, 2009). Teenagers who have positive attitudes towards sexual risk behaviors, such as having multiple sexual partners, are more likely to engage in such behaviors given the opportunity (BraunCourville \& Rojas, 2009; Lo \& Wei, 2005). The current study also considered sex for pay, alcohol and drug use prior to sexual intercourse as well as having sex with strangers as forms of high risk sexual behavior as forms of high risk sexual behaviors. In addition, sexual intercourse was also conceptualized as anal, vaginal, or oral contact with a person of the opposite sex or same sex. 


\section{PORN CONSUMPTION AND SEXUAL RISK-TAKING}

\section{Statement of the Problem}

The current study examined the relationships between pornography consumption and sexual risk behavior. Previous studies have critically examined the correlation between consumption of pornography and engagement in sexual risk-taking (e.g., Nelson et al., 2014; O’Hara, Gibbons, Gerrard, Li, \& Sargent, 2012 ; Peter \& Valkenburg, 2006; Rosser et al., 2013; Sinkovic et al., 2013; Træen et al., 2015; Wright \& Randall, 2012). However, most of the studies done previously lacked a well-defined age range of participants. Many studies classified their participants using non-specific age range like 18 years and above (e.g., Nelson et al., 2014; Træen et al., 2015; Wilkerson et al., 2012) or very broad age range like $18-87$ years (Wright \& Randall, 2012).

Secondly, prior studies also measured SEM use within a very broad timeframe like six months (e.g., Peter \& Valkenburg, 2006; Peter \& Valkenburg, 2008), 12 months (e.g., Brown \& L'Engle, 2009; Rogalo \& Tyden, 2003; Nelson et al., 2014; Svedin et al., 2011; Sinkovic et al., 2013) or even 12 - 24 months (e.g., Lo et al., 1999; Lo \& Wei, 2005). The current study addressed these methodological gaps first by focusing on participants who are aged $18-25$ years and secondly by measuring the frequency of SEM use within three-month period.

The focus on adolescents and young adults in the current study was based on the developmental challenges or vulnerability that accompanies this stage of development. Given their sexual curiosity at this stage, adolescents often use the media as their primary source of information in matters regarding sex (Bleakley, Hennessy, Fishbein \& Jordan, 2008). Peter and Valkenburg (2011) argued that adolescence as a phase in development specifically renders individuals vulnerable to the impact of sexually explicit media because of the curiosity that comes with the stage. 


\section{PORN CONSUMPTION AND SEXUAL RISK-TAKING}

Sexual content in the media mold teenagers' attitudes and behaviors in a manner that often has lifelong influence (Ybarra \& Mitchell, 2005). This means that to the curious adolescents the media might be an authoritative source of information on sexual matters almost to the level of a trusted friend or peer group members (Bleakley et al., 2008). In the context of media, the current study also took into consideration the changing tide of technology in regard to information access among young adults, how this change influences access to pornography and whether there is a significant relationship between sexually explicit media use and sexual risk behavior. 


\section{PORN CONSUMPTION AND SEXUAL RISK-TAKING}

\section{Chapter II}

\section{Literature Review}

Theoretical framework. The current study was anchored on Bandura's social learning theory (1977). This theory provided a framework which was used to demonstrate how sexually explicit media use correlates with sexual risk-taking among adolescents and emerging adults. It also provided a framework within which the findings of the study was interpreted and analyzed.

Albert Bandura's social learning theory. Bandura's social learning theory is pegged on the idea that learning within the environment begins with observation (Bandura, 1977). This is referred to as observational learning. At the observation stage, the observer watches and listens before rehearsing and imitating the said behavior. Bandura terms the person being observed as the 'model' and the process through which the person learns the behavior as 'modelling'. For effective modeling to occur, certain conditions must be in place (Bandura, 1977). For example, modelling cannot occur unless the observer pays close attention to what is being done or being said by the model. Attention is therefore a key component of social learning (Bandura, 1977). In addition to paying attention, the observer should also be able to encrypt the information into their memory. Bandura (1977) refers to this component as retention. Proper retention also enables the observer to retrieve the information easily from their long-term memory for future use. Since modelling is about reproducing the action that was observed on a model, the observer should have the physical abilities to put into practice what has been observed. This component is referred to as physical reproduction. All these three components (i.e., attention, retention, and reproduction) may not work if there is no motivation or reinforcement. The observer should hope to receive some benefit that comes with modelling the said behavior (Bandura, 1977).

As a test of this theory, Bandura used an experiment to demonstrate how children learn aggressive behavior. Bandura's experimental study hypothesized that children who were exposed 


\section{PORN CONSUMPTION AND SEXUAL RISK-TAKING}

to aggressive behavior would model aggression more than those who were exposed to a nonaggressive behavior. Bandura's famous (1961) Bobo doll experiment was carried out using three groups of children. One group was exposed to an adult displaying aggressive behavior, another group was shown an adult modelling a passive, non-aggressive behavior and third group which was the control group was not exposed to anything. When the children were left on their own, children who were exposed to aggressive adult model meted out similar aggression on the Bobo doll. The children in the control group or those who were in passive group did not display any aggression. This experiment demonstrated the power of social learning in modelling behavior.

In the context of sexual behavior, the characters in the sexually explicit media become the model of sexual behavior. A study done by Nordin, Hanson, and Tyden (2005) revealed that high exposure to sexually explicit media increased the likelihood of people to reenact the same sexual acts in real life. As reported by Nordin and colleagues (2005), heavy pornography consumers were more likely to perceive pornography actors as sexual models and to reenact their sexual acts in real life, just like children in the Bobo doll experiment reenacted aggression. Based on social learning theory, sexually explicit media can facilitate the process of sexual behavior modelling or sexual socialization especially for the teenaged consumers.

Although prior studies show a possible link between sexually explicit media use and sexual risk behavior outcomes, the processes involved in that link might not be as direct as assumed. There might be other mediating factors that contribute to the sexual behavior outcomes. For example, individuals who have inclination towards sexual novelty might engage in sexual risk-taking even in the absence of exposure to sexually explicit media. Sinkovic et al. (2013) described this inclination to sexual novelty as "sexual sensation seeking" (p. 634) and pointed out that individuals inclined towards sexual sensation seeking were vulnerable to sexual risk- 


\section{PORN CONSUMPTION AND SEXUAL RISK-TAKING}

taking even in the absence of pornography consumption.

Other factors that might mediate the relationship between sexually explicit media use and sexual risk-taking are individual's temperament, religious beliefs, and cultural values (Brown \& L'Engle, 2009). Furthermore, the direction of the relationship between the two variables (i.e., SEM use and sexual risk-taking) is not clearly established in the prior studies. Lo and Wei (2005) argued that teenager's desire to seek pornography might also be driven by their engagement in sexual risk-taking and likewise their sexual risk behavior might be motivated by their sexually explicit media use. There is still scarcity of information especially given that only one study in the reviewed literature (i.e., Bleakley et al., 2008) explored the bidirectional relationship between pornography consumption and sexual risk-taking. Bidirectional relationship between sexually explicit media use and sexual risk-taking is indeed a research direction that future studies could consider.

Relationship between sexually explicit media and sexual risk behavior. Studies have been done to investigate the impact that sexually explicit media has on young people's sexual behavior. However, the actual impact that sexually explicit media has on a person's sexual behavior has remained controversial (Ybarra \& Mitchell, 2005). While some studies reveal a clear relationship between sexually explicit media use and sexual risk behavior (e.g., Lo et al., 1999; Lo \& Wei, 2005; Morgan, 2011; Nelson et al., 2014; O’Hara et al., 2012; Stein et al., 2012; Svedin, Akerman \& Priebe, 2011; Wingood et al., 2001), others show that there is no significant relationship between sexually explicit media use and sexual risk behavior (e.g., Luder et al., 2011; Peter \& Valkenburg, 2006; Wright \& Randall, 2012). The current study examined the relationship between sexually explicit media use and sexual risk-taking measured using key outcome variables like multiple sexual partners, frequency of condom use and high risk sexual 


\section{PORN CONSUMPTION AND SEXUAL RISK-TAKING}

behavior.

Secondly, prior studies also measured sexually explicit media use within a very broad timeframe like six months (e.g., Peter \& Valkenburg, 2006; Peter \& Valkenburg, 2008), 12 months (e.g., Brown \& L'Engle, 2009; Rogalo \& Tyden, 2003; Nelson et al., 2014; Svedin et al., 2011; Sinkovic et al., 2013) or even 12 to 24 months (e.g., Lo et al., 1999; Lo \& Wei 2005). This time lapse compromises the accuracy with which the participants report their risk behavior. The current study addressed this methodological gap by focusing on the age bracket of 18 to 25 years.

Multiple sexual partners. Previous studies have reported a significant relationship between SEM use and engagement with multiple sexual partners. In this section, the existing literatures on multiple sexual partners are reviewed. However, the age range in the studies reviewed here is broader than the age range of the current study. The conclusions from these prior studies should therefore be drawn and interpreted within the framework of this limitation.

A study done by O'Hara et al. (2012) examined how consumption of movie-based pornography correlated with how early or late teenagers began engaging in sexual intercourse as well as their inclination towards sexual risk-taking. O’Hara and colleagues (2012) hypothesized that exposure to pornographic movies at the onset of adolescence would be associated with increased experimentation with casual sexual partners and increased engagement in unprotected sex. The data was gathered from 1,228 respondents using a six-wave longitudinal approach in which participants were studied at Time 1 up to Time 6. The respondents were aged 12-14 years in the first wave and by Time 6 they were aged 18-21 years. The sample included both sexes and was predominantly European American. At Time 1, the study measured the respondents' level of pornographic movie consumption by finding out the number of pornographic movies each 


\section{PORN CONSUMPTION AND SEXUAL RISK-TAKING}

respondent had been exposed to. At Time 6, the respondents gave a self-report on their sexual risk behavior. The key measures used for sexual risk-taking were,-number of casual sexual partners, number of unprotected sexual encounters and multiple sexual partners. The study revealed a significant correlation between early exposure to pornographic movies at Time 1 and high sexual risk behavior at Time 6. Participants who had been exposed to pornographic movies at Time 1 were more likely to report having sex with multiple partners, and having casual unprotected sex at Time 6. Although the association between exposure to pornographic movies and sexual risk-taking existed for both males and females, the effect of exposure was greater among male than female respondents. These findings provide clear evidence a longitudinal association between SEM use and sexual risk-taking. The findings also reflect clear gender differences with SEM use having a greater impact on the males than the females.

Apart from longitudinal studies, online cross-sectional studies have also been used to study the connection between online exposure to SEM use and multiple sexual partners. Specifically, Wright and Randall (2012) examined the association between SEM use and sexual risk behavior among American male adults. In their study, it was hypothesized that consumption of online sexually explicit media would correlate positively with the number of sexual partners as well as involvement in sex outside of marriage. It was also predicted that there would be a significant negative association between condom use and SEM use. The final hypothesis was about the link between SEM use and engagement in paid sex. The data used in this study was extracted from the General Social Survey (GSS). These data were collected in different surveys carried out in 2000, 2002, and 2004 in which a total of 1,079 adult males aged 18-87 participated $\left(M_{\text {age }}=41\right.$ years $)$. Using self-report measures, the participants reported the frequency of their pornography access online within one month prior to the study. Additional questionnaires were 


\section{PORN CONSUMPTION AND SEXUAL RISK-TAKING}

also used to report the number of intimate partners the respondent had had within five years prior to the survey, use or no use of condoms during the previous sexual encounter, and paying or being paid for sex. The respondents who were married also reported whether they had had sexual intercourse with another person other than their spouse. Since age influences sexual behavior and sexual risk-taking, the study controlled for age. The consumption of internet pornography was measured using one item in which the respondents were required to indicate how frequently in the previous 30 days they had visited a pornographic website to view sexually explicit content. Since Whites and non-Whites often have varying sexual behavior patterns and different pornography consumption patterns, ethnicity was controlled for. The findings of this study revealed a positive correlation between SEM use and number of sexual partners. The study findings also showed a significant correlation between pornography consumption and engagement in sex outside marriage. Married respondents who were exposed to online pornography were more likely to report having had sex with another person other than their spouse. Consistent with previous studies, the findings of this study also revealed a positive correlation between consumption of online pornography and paying for sex. Respondents who were exposed to online sexually explicit media reported having paid for sex or been paid to give sex. The connection between consumption of pornography and involvement with multiple sexual partners was especially clear among married respondents who reported high likelihood to have sex with another person other than spouse after exposure to sexually explicit media. These findings are consistent with those of prior studies that report significant association between SEM use and sexual risk-taking.

In another investigation, Morgan (2011) analyzed the frequency of exposure to sexually explicit media and its influence on sexual risk behavior of both males and females. It was 


\section{PORN CONSUMPTION AND SEXUAL RISK-TAKING}

hypothesized that higher frequency of pornography exposure would predict the number of lifetime sexual partners as well as the number of casual sexual partners. A total of 782 college students aged $18-30$ years $(M$ age $=19.9$ years $)$ participated in the online survey. The sample included both sexes and was predominantly White. The key constructs in this study were frequency of sexually explicit media use and sexual risk-taking. In Morgan's (2011) study, SEM use was measured using a single item that required the participants to indicate how frequently they viewed sexually explicit media. Sexual risk-taking was measured using the number of sexual partners the respondent had had sexual intercourse with within one year prior to the study and the number of times they engaged in sexual intercourse with uncommitted or casual sexual partners. The outcome of these SEM use variables were analyzed based on gender. Consistent with previous research, the study results revealed a significant relationship between frequency of exposure to pornography and sexual risk-taking. The respondents who reported higher frequency of exposure to sexually explicit media were also more likely to report higher number of lifetime sexual partners as well as higher numbers of casual (uncommitted) sexual partners. The findings of this study also revealed a striking significant difference in frequency of exposure between male and female respondents. On average, male participants were exposed to pornography once in seven days while female respondents viewed pornography once in 12 months. In sum, the findings of this study provide empirical evidence of the potential influence that SEM use has on a person's engagement with multiple sexual partners. The findings also lend support to the results of prior studies regarding the gender differences in SEM use.

Additional studies carried out with female only participants have however revealed different findings in regard to multiple sexual partners. Rogala and Tyden (2003) used a random survey to examine how sexually explicit media use correlated with sexual risk behavior of young 


\section{PORN CONSUMPTION AND SEXUAL RISK-TAKING}

women in Sweden. In this study, it was hypothesized that there would be positive correlation between sexually explicit media use and sexual risk-taking. The study was done using data gathered by nurses from a Stockholm-based family planning outpatient clinic. A total of 1,000 women aged 25 years and below participated in the study. The nurses gathered data for nine months using questionnaires that the respondents filled in during their clinic visits. To measure sexually explicit media use, a two-item questionnaire was used in which the respondents reported if they had ever sought out pornographic content in magazines, film, or in the Internet. In addition to this, the participants also reported the frequency of their exposure based on terms like "rarely", "occasionally", or "frequently". A total of 75\% of the respondents reported having had at least three or less sexual partners within 12 months prior to the study, $94 \%$ had engaged in oral sex and $47 \%$ had engaged in anal intercourse. Among all the behavior outcomes, the findings of the study showed a significant correlation between exposure to sexually explicit media and the respondent's engagement in anal sex. There was however, no significant correlation revealed between exposure to sexually explicit media and multiple sexual partners in this study. The lack of significant association between SEM use and engagement with multiple sexual partners in this study is inconsistent with findings of prior studies that found a correlation between the two variables. This finding also further supports the inconsistency in study findings reported in prior literature in regard to SEM use and sexual risk-taking.

Overall, the studies reviewed under multiple sexual partners show evidence of significant relationship between sexually explicit media use and sexual risk-taking. However, there is no uniformity of findings across the studies reviewed. One study that involved female only participants did not find a significant relationship between sexually explicit media use and engagement with multiple sexual partners (Rogala \& Tyden, 2003). Study findings also revealed 


\section{PORN CONSUMPTION AND SEXUAL RISK-TAKING}

significant gender differences with the males reporting higher levels of pornography

consumption than the females (e.g., Morgan, 2011; O'Hara et al., 2012). Although studies across

the literature are relatively consistent in their findings, it is evident that there is no clearly

defined age-range upon which the studies were focused. The current study contributes to the

existing literature by examining the consumption of sexually explicit media and its impact

among $18-25$ year old young adults.

Frequency of condom use. Apart from multiple sexual partners, previous studies show evidence of inconsistent condom use as being correlated with sexually explicit media use. In this section, literatures on frequency of condom use in connection with sexually explicit media use are reviewed. However, the age range in the studies reviewed here is different from the age range of the current study which is focused on $18-25$ years. Some studies reviewed focus on participants who are below 18 years while other studies use broad none specific categories like 18 years and above.

A study done by Wingood, DiClemente, Harrington, Davies, Hook, and Oh (2001) analyzed how the consumption of pornographic movies influenced African American teenaged girls' (age 14 - 18 years) sexual behavior and their attitudes towards condom use. In their study, Wingood and colleagues (2001) hypothesized that high consumption of pornography would correlate negatively with condom use. They also hypothesized that there would be a significant association between pornography consumption and multiple sexual partners. The participants were recruited from different teen reproductive health clinics and school health education programs. A total of 522 African American teenaged girls participated in the survey in which face-to-face interview was used to gather information on the participant's sexual behavior. To measure their sexually explicit media use, the participants were asked whether they had watched 


\section{PORN CONSUMPTION AND SEXUAL RISK-TAKING}

pornographic movies within 90 days prior to the survey. The sexual risk behaviors that were reported included multiple sexual partners, history of sexually transmitted infections and condom use in their most recent sexual intercourse. The study found a significant correlation between consumption of pornographic movies and absence of condom use during the participants' latest sexual intercourse. In addition to this, participants who reported high consumption of pornographic movies were more likely to report having had more than one sexual partner within six months prior to the survey. The study findings also revealed a significant correlation between pornographic movie consumption and sexually transmitted infections. In the final analysis, participants who reported high consumption of pornographic movies, were more likely to have had unprotected sex with multiple sexual partners and more likely to report a history of sexually transmitted diseases. The significant correlation between pornographic movie consumption and sexually transmitted infections indirectly showed that consumption of pornographic movies also correlated with inconsistent condom use.

Additional studies done among men having sex with men have also shown a correlation between SEM use and low condom use. For example, Stein, Silvera, Hagerty, and Matmor (2012) carried out an online survey to find out the relationship between exposure to SEM showing unprotected anal intercourse and low condom use among men having sex with men. Stein and colleagues (2012) hypothesized that being exposed to sexually explicit content online, that showed unprotected anal intercourse would correlate with the likelihood to be involved in unprotected anal intercourse. A total of 821 adult men who were having sex with men in nonmonogamous relationships participated. In Stein and colleagues (2012) study, SEM use was measured using a detailed scale that required respondents to indicate whether they had viewed pornographic content or not, the duration spent viewing pornography in terms of minutes per 


\section{PORN CONSUMPTION AND SEXUAL RISK-TAKING}

week and the amount of pornographic content viewed that depicted protected intercourse or intercourse without a condom. The respondents also reported the frequency of their exposure and how long they spent in each viewing session. To gauge sexual risk-taking, the participants reported the number of male partners they had had sexual intercourse with within 90 days prior to the study. They also reported the number of times they had used condoms in their sexual encounters within 90 days prior to the study. The study findings showed a statistically significant correlation between exposure to pornographic scenes of unprotected anal intercourse and sexual risk-taking among men having sex with men. The respondents who had watched pornographic scenes of unprotected anal intercourse also reported their involvement in unprotected anal intercourse within 90 days prior to the study. Unlike other studies that focused on condom use only, Stein and colleagues also required the respondents to report the length of their viewing session and the genre of sexually explicit media they preferred to consume which was either protected or unprotected anal intercourse. The findings showed evidence of a correlation between exposure to sexually explicit media depicting unprotected intercourse and inconsistent condom use among men having sex with men.

A related study carried out in Norway also yielded evidence in support of low condom use and sexually explicit media use correlation. Træen et al. (2015) examined the correlation between sexually explicit media use and condom use among men who have sex with men in Norway. They hypothesized that exposure to pornographic scenes depicting unprotected anal sex would positively correlate with engagement in unprotected anal intercourse. A total of 507 respondents aged 18 years and above participated in the online survey. The goal of the study was to examine how men having sex with men in Norway consumed gay-type of pornography and how that pornography consumption correlated with their sexual risk-taking. In their study, Træen 


\section{PORN CONSUMPTION AND SEXUAL RISK-TAKING}

and colleagues (2015) assessed sexually explicit media use using both frequency of exposure within 90 days prior to the study and how long their viewing sessions lasted. Consistent with previous studies, the findings revealed a significant correlation between sexually explicit media use and sexual risk-taking among men having sex with men. It was found that participants who were exposed to scenes depicting unprotected anal intercourse were more likely to report higher levels of sexual risk behavior as measured by infrequent or no condom use as well as multiple male sexual partners. Unlike prior studies that examined SEM use in general, this study examined the impact that specific types of SEM had on sexual risk-taking. The findings show empirical evidence that exposure to SEM depicting scenes of unprotected sexual intercourse was associated with higher levels of sexual risk-taking than exposure to SEM depicting scenes of protected sexual intercourse.

Similarly, some studies have specifically examined men who prefer to consume only SEM depicting unprotected anal intercourse. Nelson, Simoni, Morrison, George, Leickly, Lengua, and Hawes (2014) study is an example of a research that examined the relationship between pornography consumption and preferences for unprotected sex among men who have sex with men. Nelson and colleagues (2014) hypothesized that consumption of pornography depicting unprotected anal sex would positively correlate with preference for unprotected anal intercourse. It was a cross-sectional online survey in which a total of 1,170 men participated. The respondents in this study were predominantly Caucasian male adults aged 18 years or more. They also had to meet additional requirements like having had sex with a male partner, having used online dating sites to 'hook up' with a male sexual partner and having consumed pornography online within 12 months prior to the study. Using an online questionnaire, the respondents reported the number of sexual partners they had had within three months prior to the 


\section{PORN CONSUMPTION AND SEXUAL RISK-TAKING}

study, how old they were during their first sexual encounter with a male partner and how often they had used a condom within three months prior to the study. To report sexually explicit media use respondents identified the different types of pornography they had consumed within three months prior to the study. The genres were pornographic photos, videos, and sexually explicit stories. In addition to the frequency of their pornography consumption in a week, or a month, the respondents also reported the length of each viewing session. It ranged from less than 60 seconds to 60 minutes and above. The study findings revealed a significant correlation between exposure to pornographic scenes showing unprotected sex and participants' involvement in unprotected anal intercourse. The findings provide further empirical evidence that the type of SEM used also shapes sexual risk-taking.

Apart from examining the relationship between SEM use and inconsistent condom use, some studies have also analyzed what determines the reenactment of the behavior watched in sexually explicit media among men having sex with men. To carry out this kind of analysis, Wilkerson, Iantaffi, Smolenski, Brady, Horvath, Grey, and Rosser (2012) used an online focus group survey. They hypothesized that men who have sex with men (MSM) were likely to reenact sexual scenes watched on sexually explicit media if they found such scenes sexually arousing and if they found an intimate partner desiring to put into practice such sexual scenes with them. A total of 227 men aged 18 or older participated in the study. The study was conducted using an online focus group discussion which lasted 90 minutes. The participants were first asked to report the type of pornography they consumed, and the medium through which they consumed it (e.g., pornographic magazine, film, online). The responses were then plotted in a graph format and disseminated among participants to stimulate further discussions. After the focus group discussion, participants were asked to give their responses to questions designed to 


\section{PORN CONSUMPTION AND SEXUAL RISK-TAKING}

follow up on issues that had dominated the focus group discussion. It was found that a number of respondents used sexually explicit media to quench their thirst for sex especially when they were feeling lonely. A total of 19 respondents reported frequently reenacting scenes they had watched on sexually explicit media. The study findings established a clear link between SEM use and sexual risk behavior among MSM.

Although previous studies showed consistent evidence of relationship between low condom use and SEM use among males, some studies involving females have not found this link. Luder, Pittet, Berchtold, Akre, Michaud, and Suris (2011) hypothesized that exposure to sexually explicit media would positively correlate with engagement in sexual risk behavior. A total of 6,054 respondents aged $16-20$ years participated. The investigators used four key variables to assess behavior outcomes. The variables were sexual intercourse before the age of 15 , condom use in the previous sexual intercourse, number of sexual partners, and pregnancy (i.e., having become pregnant or having made a partner pregnant). SEM use was measured on a scale in which the respondents were expected to categorize their pornography use as less than a day per week, one day per week, more than a day per week but not every day, and every day use. The findings of the study showed a significant relationship between online exposure to sexually explicit media among males and the absence of condom use during the participant's last sexual encounter preceding the study. There was however no significant relationship between pornography consumption and the absence of condom use for female participants. The findings demonstrated that whereas exposure to sexually explicit media correlated with low condom use among males it did not necessarily have a similar impact on females.

Overall, studies across the literature show a statistically significant correlation between sexually explicit media use and low condom use (e.g., Nelson et al., 2014; Stein et al., 2012; 


\section{PORN CONSUMPTION AND SEXUAL RISK-TAKING}

Træen et al., 2015; Wingood et al., 2001; Wilkerson et al., 2012). These findings have been revealed among heterosexual participants as well as men having sex with men (MSM). Studies done among MSM specifically showed exposure to low condom use especially correlated with consumption of pornographic movies that depicted unprotected anal intercourse (i.e., Nelson et al., 2014; Stein et al., 2012; Træen et al., 2015; Wilkerson et al., 2012). The above findings clearly show that the type of pornography being consumed also influences sexual risk behavior. Just like the literature for multiple sexual partners, the literature on consistent condom use show significant gap on age specification. Most studies across the literature use broad terms to describe the age range. For example, '18 years or older' (e.g., Nelson et al., 2014; Træen et al., 2015; Wilkerson et al., 2012). Another broad phrase is 'adult men' (e.g., Stein et al., 2012). The current study addresses this methodological gap by focusing on the potential influence of pornography consumption on consistent condom use among 18 - 25 year old emerging adults.

High risk sexual behavior. Apart from inconsistent condom use and multiple sexual partners, additional categories of sexual risk behaviors have also been studied. One such category is high risk sexual behavior. Peterson et al. (1992) identified sex for pay and use of injection drugs as examples of high risk sexual behavior. However, Vanable et al. (2004) included sex with strangers in addition to alcohol and drug use prior to sexual intercourse as forms of high risk sexual behavior. The current study considered sex for pay, alcohol and drug use prior to sexual intercourse as well as having sex with strangers as forms of high risk sexual behavior. In this section, the literature on high risk sexual behavior are reviewed. However, the age range in the studies reviewed here is broader (i.e., 18 year and older) than the age range of the current study (18 - 25 years). The conclusions and interpretations should therefore be made within the framework of this limitation. 


\section{PORN CONSUMPTION AND SEXUAL RISK-TAKING}

A study done by Svedin, Akerman, and Priebe (2011) examined the impact that pornography had on the lives of regular pornography consumers based on the frequency of exposure to sexually explicit media. In their cross-sectional study, Svedin and colleagues (2011) hypothesized that high levels of sexually explicit media use would correlate with high risk sexual behavior. The survey was done in Sweden and 200 males aged 18 and above took part. Using self-reported measures the researchers assessed the influence that pornography consumption had on sexual behavior of male adults. To measure sexually explicit media use, participants were asked if they ever sought out sexually explicit media in any form. Those who responded in the affirmative were then asked about the frequency of their sexually explicit media use ranging from once a year to more or less every day. A different measure was used to gauge the influence of pornography on the individual's sexual behavior. The participants were also expected to give a self-report on whether they had a desire to reenact the sexual scenes they had watched. The desire to reenact sexual scenes watched was associated with high pornography consumption and was statistically higher among high consuming group of boys than low-consumers. Compared to non-consumers, more heavy consumers also reported to have either sold or paid for sex. The findings of this study showed evidence of a relationship between consumption of pornography and high risk sexual behavior especially sex for pay.

In another investigation, Sinkovic, Stulhofer and Bozic (2013) examined the relationship between SEM use and high risk sexual behavior using both male and female participants. They specifically used a cross-sectional design to examine the impact that early exposure to SEM had on the sexual risk behavior of 1,005 Croatian youth aged 18-25 years. The researchers hypothesized that early exposure to pornographic media would correlate with higher sexual risktaking. SEM use was assessed using three items (i.e. participant's age when they got exposed for 


\section{PORN CONSUMPTION AND SEXUAL RISK-TAKING}

the first time, how often they had been exposed within the previous 12 months and how significant pornography was in their life). There were also indicators to measure the participant's sexual risk behavior in terms of condom use, the number of sexual partners and high risk sexual behavior like having sex with strangers. The study's findings revealed that males were more likely to be exposed to pornography at an earlier age than were females. There was equally another marked gender difference in the frequency of exposure with $22 \%$ males reporting exposure to pornography multiple times a week as compared to only $3 \%$ of females. More males than females also rated pornography as playing a key role in their sexual lives. This study revealed a significant link between reported sexual risk-taking (sex with strangers) and early exposure to sexually explicit media. It was found that the timing of the first exposure and the frequency of pornography use were significant in predicting sexual risk-taking. Respondents who reported early exposure to sexually explicit media were more likely to report higher sexual risktaking as compared to those who reported late exposure. Unlike previous studies, the findings of this study show empirical evidence that the timing of the first exposure to SEM is an essential factor. Early exposure to SEM clearly corresponds with higher that sexual risk-taking.

Taken as a group, these studies show a significant relationship between SEM use and engagement in high risk sexual behavior. Specifically, studies reviewed showed a significant correlation between SEM use and sex for pay (e.g., Svedin et al., 2011) as well as sex with strangers (e.g., Sinkovic et al., 2013). Consistent with previous studies, there were clear gender differences with males showing higher levels of SEM use than the females (e.g., Sinkovic et al., 2013).

Sexual attitudes and pre-coital behaviors. Previous studies done on sexual risk behavior and sexually explicit media use have focused on inconsistent condom use, multiple 


\section{PORN CONSUMPTION AND SEXUAL RISK-TAKING}

sexual partners and high risk sexual behavior. Some of the studies have looked at these variables concurrently while a few have focused on just one variable. In the current study sexual risktaking in terms of condom use, multiple sexual partners and high risk sexual behavior are examined. However, in addition to these variables the literature on sexual attitudes and pre-coital sexual behaviors have also been explored. Although, sexual attitude is not directly classified as a sexual risk behavior variable, studies have revealed that sexual attitude prepares ground for potential sexual risk behavior (Peter \& Valkenburg, 2008). In this section, the literature on sexual attitude and pre-coital behavior are reviewed. However, the age range in the studies reviewed here is broader than the age range of the current study which focuses on 18-25 years. The conclusions and interpretations should therefore be made within the framework of this limitation.

Peter and Valkenburg (2006) demonstrated a significant difference between males and females in a study which measured the frequency of intentional exposure to sexually explicit media and the participants' attitude towards casual sex. In their study, Peter and Valkenburg (2006) hypothesized that adolescents' exposure to sexually explicit online material would correlate positively with their positive attitudes towards casual sex. The authors conducted an online survey in which 471 Dutch adolescents aged 13-18 participated. They measured the frequency of intentional exposure to sexually explicit media and how that exposure correlated with the participants' attitude towards casual sex without commitment. To assess SEM use, participants reported how regularly they viewed pornographic media (e.g., pictures of exposed genitals, movies showing genitals, pictures showing sexual acts or movies depicting sexual activities) online within the previous six months. The study findings demonstrated that there was no direct association between online exposure to SEM and casual attitudes towards sex. The study results however showed that the association between the two variables was mediated by 


\section{PORN CONSUMPTION AND SEXUAL RISK-TAKING}

the adolescent's assessment of the degree of realism of the sexually explicit media. Furthermore, the findings also showed that the adolescents (largely males) who were exposed to sexually explicit media more often were likely to perceive the material as realistic. Such adolescents were more likely to have a recreational attitude towards sex than their counterparts who were exposed less frequently. Hence the positive attitude toward casual sex was an indirect result of regular exposure to SEM. Although the current study did not assess the participant's perception of SEM, the significant association between SEM use and sexual risk-taking lends support to findings of prior studies.

In 2008, Peter and Valkenburg conducted another follow up study to examine how sexually explicit media use influenced sexual attitudes. They analyzed SEM use and how it correlated with accumulating multiple sexual partners among Dutch teenagers. They also hypothesized that higher levels of SEM use would have a significant correlation with positive attitude towards multiple sexual partners. The study was conducted through a two month online survey in which 2,343 respondents aged 13-20 years participated. To assess SEM use, participants reported how regularly they viewed pornographic content (e.g., pictures of exposed genitals, movies showing genitals, pictures showing sexual acts or movies depicting sexual activities) online within six months prior to the study. The findings from this study revealed a significant association between SEM use and adolescents' desire for casual multiple sexual partners. Teens who reported high levels of sexually explicit media use were more likely to view involvement with multiple casual sexual partners positively. In sum, there is evidence that supports the association between SEM use and positive attitude towards multiple sexual partners. This link was investigated in the current study. The current study however, examined actual engagement with multiple sexual partners, not just positive attitude towards the behavior. 


\section{PORN CONSUMPTION AND SEXUAL RISK-TAKING}

In another investigation, Lo, Neilan, Sun, and Chiang (1999) examined the influence that exposure to sexually explicit media had on the sexual attitude of teenagers in Taiwan. It was hypothesized that high levels of SEM use would be associated with positive attitude towards multiple sexual partners. To assess their SEM use, the participants were shown a list of 10 different SEM and were expected to report how regularly they had viewed each within the previous 12 months or 24 months. The study findings revealed that SEM use had a significant correlation with a positive attitude towards sexual risk behavior. The findings' analysis also showed that SEM use correlated strongly with positive attitude towards multiple sexual partners. Participants who reported high levels of SEM use were more likely to report a positive attitude towards multiple sexual partners. These findings support those of prior studies that found an association between SEM use and positive attitude towards multiple sexual partners. This association also supports a link between SEM use and engagement with multiple sexual partners that was examined in the current study.

Apart from online surveys, longitudinal studies have also been used to study the correlation between exposure to sexually explicit media and sexual attitudes. Specifically, Brown and L'Engle (2009) used a two-wave longitudinal approach to examine the influence that early exposure to sexually explicit media had on the sexual attitudes of American teenagers. The study was designed to analyze the degree to which early exposure to sexually explicit media in adult magazines, pornographic movies and the Internet could predict sexual behaviors and attitudes among early adolescents. In their study, Brown and L'Engle (2009) hypothesized that male and female teenagers who had been exposed to sexually explicit media during early adolescence years were more likely to report having tried out oral sex as well as venturing into sexual intercourse early. 


\section{PORN CONSUMPTION AND SEXUAL RISK-TAKING}

A total of 3,000 ( $7^{\text {th }}$ and $8^{\text {th }}$ graders $)$ students participated in the study. The sample was predominantly Whites and African Americans. The mean age of the respondents was 13 years at Time 1 and by Time 2 during follow up interview their mean age was 15.6 years. Three-itemed questionnaire was used to assess the participant's exposure to sexually explicit media. The items required the participants to report how often they had viewed X-rated movies, read pornographic magazines, or viewed pictures with exposed genitals online within the previous one year. A bigger percentage of the males than females reported using computers or the Internet to view SEM content. Females reported higher viewing of X-rated movies, viewing naked pictures from the Internet and adult magazines than did males. Male participants who reported high levels of SEM use at Time 1 were more likely to have been engaged in oral sex and vaginal or anal intercourse at Time 2. The study findings also showed that participants who had been exposed to SEM had positive attitude towards sexual exploration and noncommittal sexual behavior. These findings show empirical link between SEM use and sexual risk-taking; an association that was examined in the current study.

In addition to online surveys and longitudinal studies, the link between sexual attitudes and SEM use has also been investigated experimentally. Jonas, Hawk, Vastenburg, and Groot (2014) used an experimental design to examine the link between SEM use and the attitude towards protected sex among men having sex with men. They hypothesized that the sexual behavior of men having sex with men would be significantly linked to the type of sexually explicit media they were exposed to. Men who were exposed to pornographic DVDs depicting scenes of unprotected sex were more likely to have stronger preference for unprotected sex than men who had been exposed to pornographic DVDs depicting scenes of protected sex. The participants were 220 men aged $18-67$ who were having sex with men. The group of 


\section{PORN CONSUMPTION AND SEXUAL RISK-TAKING}

participants that watched unprotected sexual scenes showed higher preference for unprotected sex as compared to the group that watched pornographic DVD scenes of protected sex. From the findings of this study, the relationship between SEM use and sexual attitude was also shaped by the type of sexually explicit media the participants were exposed to. The findings of this study provide a strong empirical evidence of the link between SEM use and sexual risk-taking. The experimental approach also shows that the type of SEM consumed shapes sexual risk-taking behavior.

Another related area that has attracted research is then relationship between SEM use and pre-coital sexual behavior. Lo and Wei (2005) examined the effects of online exposure to SEM on the sexual behavior of Taiwanese teenagers in regard to the gender differences in levels of SEM use. It was hypothesized that high levels of exposure to online SEM content was likely to correlate with risky sexual behavior among teenagers. A total of 2,001 teenagers $(M$ age $=16)$ participated in the survey. To assess their SEM use, participants reported how regularly they had intentionally used the Internet to access SEM content within the $12-24$ months prior to the study. The study findings showed a statistically significant link between exposure to sexually explicit online content and adolescents' engagement in pre-coital sexual behavior. Gender played a role with males reporting higher levels of SEM use than the females. Male participants also exhibited more positive attitude towards casual sexual relation with non-committed partners than the female participants. Higher levels of SEM use was also significantly associated with endorsement of sex outside marriage. Participants who were exposed to high levels of SEM were more likely to report a positive attitude towards sex outside marriage than those who were less exposed to SEM. The findings of this study provide additional evidence of a significant link between SEM use and sexual risk-taking. In addition, gender also played a role in this 


\section{PORN CONSUMPTION AND SEXUAL RISK-TAKING}

association with males reporting higher SEM use than the females. The gender difference between males and females in SEM use was examined in the current study.

The difference in levels of SEM use based on gender has been found in previous studies as well. Braun-Courville and Rojas (2009) used a cross sectional survey to investigate how exposure to online SEM influenced teenagers' attitude towards casual sex and their sexual behaviors, such as lack condom use for males or birth control for females, engaging in anal sex, having multiple sexual partners, having sex under the influence of alcohol or substance, having a history of sexually transmitted infections, paying or being paid for sex and searching for a new sexual partner online. In their study, it was hypothesized that exposure to online pornography would positively correlate with the teenager's positive attitude towards casual sex. A total of 433 respondents aged $12-22$ years were recruited from high risk populations in New York City. To assess SEM use, participants were asked to report how regularly they had viewed pornographic content online within 90 days prior to the study. The study findings revealed a positive attitude towards casual sex that correlated strongly with exposure to online pornography. Similarly, teenagers who were exposed to online pornography were more likely to report risky sexual behaviors like anal sex, having more than one sexual partner and alcohol use during the previous sexual encounter. A total of $86 \%$ of male participants visited pornographic websites as compared to $50 \%$ of female participants. This gender difference in the number of males as compared to females who had visited pornographic websites is consistent with findings from previous study done by Lo and Wei (2005) in which males reported higher levels of SEM use than the females. This study therefore shows evidence of gender difference in SEM use; a difference that was investigated in the current study.

Overall, the studies reviewed in this section showed a significant relationship between 


\section{PORN CONSUMPTION AND SEXUAL RISK-TAKING}

SEM use and positive attitude towards sexual risk-taking among adolescents (e.g., BraunCourville \& Rojas, 2009; Brown \& L'Engle, 2009; Jonas et al., 2014; Lo et al., 1999; Lo \& Wei, 2005; Peter \& Valkenburg, 2008). The studies generally found that participants who had been exposed to sexually explicit media had positive attitudes towards sexual exploration and noncommittal sexual behavior. Consistent with previous studies, there were also gender differences in the levels of SEM use se as well as sexual risk behavior outcomes. Male participants reported higher levels of SEM use than females (e.g., Braun-Courville \& Rojas, 2009; Brown \& L'Engle, 2009; Lo \&Wei, 2005). Similarly, male participants who were exposed to sexually explicit media also exhibited more positive attitude towards casual sex than their female counterparts (e.g., Brown \& L'Engle, 2009; Lo \& Wei, 2005).

\section{Conclusions and Literature Gaps}

Studies so far done on sexual risk behavior and its link with SEM use have covered a range of variables. The sexual risk behavior variables adopted by prior studies have evidently been determined by the age of participants being studied. For instance for participants aged $12-$ 18 years, sexual risk behavior has largely been measured in terms of recreational attitude towards sex (e.g., Peter \& Valkenburg, 2006), attitudes towards multiple sexual partners (e.g., Peter \& Valkenburg, 2008), deep kissing, breast touching, and genital touching (e.g., Bleakley et al., 2008; Lo \& Wei, 2005; Lo et al., 1999). In studies where young adults aged 19 - 30 years were involved, the variables of sexual risk behavior were condom use, multiple sexual partners (e.g., Lo et al., 1999; O’Hara et al., 2012; Wingood et al., 2001), engagement in anal sex (e.g., BraunCourville \& Rojas, 2009; Rogala \& Tyden, 2003), having sex with strangers (e.g., Lo et al., 1999; Sinkovic et al., 2013), history of sexually transmitted infection (e.g., Wingood et al., 2001), sex under the influence of alcohol or substance (e.g., Braun-Courville \& Rojas, 2009) and 


\section{PORN CONSUMPTION AND SEXUAL RISK-TAKING}

buying or selling sex (e.g., Svedin et al., 2011).

A number of studies have also looked at SEM use in broad sense without breaking down the different categories of sexual media and their influence on behavior. There is significant evidence revealed from prior studies that not all sexually explicit media influences correlate with sexual risk behavior in the same way (Jonas et al., 2014; Træen et al., 2015). Future studies should consider identifying the categories of pornography consumed and possible sexual risk behavior outcomes that are correlated with the pornographic content (Rosser et al., 2012). There is also a possibility that sexual risk behavior might vary across pornography consumers depending on the type of sexually explicit media they are exposed to (Rosser et al., 2012). For example, studies done on men having sex with men revealed a significant difference on how exposure to sexually explicit media depicting protected sex differed from that depicting unprotected sex in terms of their influence on sexual behavior (e.g., Jonas et al., 2014; Rosser et al., 2013; Stein et al., 2012).

Future studies should also closely examine the impact of pornography consumption based on gender. Different studies have revealed that males and females differ significantly not just on their desire to seek pornography but also on their consumption levels (e.g., Braun-Courville \& Rojas, 2009; Morgan, 2011; O’Hara et al., 2012; Peter \& Valkenburg, 2008; Rogala \& Tyden, 2003; Sinkovic et al., 2013). For example, the association between exposure to pornographic movies and sexual risk behavior existed for both males and females, but the impact of exposure was greater among male than female respondents (O'Hara et al., 2012). The lack of significant correlation between SEM use and the number of sexual partners among female respondents reported in Rogala and Tyden (2003provides a research direction that could be considered in future studies. Such studies might provide fresh insight on the different impact that sexually 


\section{PORN CONSUMPTION AND SEXUAL RISK-TAKING}

explicit media use has based on a person's sex.

Another methodological limitation is lack of ethnic balance. Most studies lack ethnic balance which lowers generalizability of the findings across different ethnic groups (e.g., Brown \& L’Engle, 2009; Nelson et al., 2014; O’Hara et al., 2012). Further, some studies have participants with such a broad range of age that is likely to skew the findings (e.g., Cournville \& Rojas, 2009). In other studies, participants are grouped under non-specific age range like 18 years and above (e.g., Nelson et al., 2014; Træen et al., 2015; Wilkerson et al., 2012) or very broad age range like 18 - 87 years (e.g., Wright \& Randall, 2012), 18 - 67 years (e.g., Jonas et al., 2014). Lumping these diverse ages together might skew the study findings.

\section{The Current Study}

The current study investigated the link between SEM use and sexual risk taking among adolescents and emerging adults. Based on theoretical framework of the social learning theory that shows the link between SEM use and sexual risk-taking through modelling, it was hypothesized that exposure to SEM would be positively associated with lower condom use, high involvement with multiple sexual partners and engagement in high-risk sexual behavior. Respondents highly exposed to sexually explicit media would show higher sexual risk-taking than those who are less exposed. It was also hypothesized that there would be gender differences not just in levels of SEM use but also in sexual risk-taking. Specifically, the males would show higher levels of sexually SEM use than the females. Similarly, males who are exposed to sexually explicit media would also show higher levels of sexual risk-taking than the females who are exposed to SEM.

Given the limited clarity accorded to age specification in prior literature, the current study contributed to the existing literature by focusing on $18-25$ years; this is an age range which has 


\section{PORN CONSUMPTION AND SEXUAL RISK-TAKING}

not been adequately investigated in prior research. The rationale for focusing on this age bracket was both methodological and conceptual. The age bracket constitutes emerging adults who are likely to have common developmental experiences as far as sexual behavior is concerned.

Secondly, prior studies also measured sexually explicit media use within a very broad timeframe like six months (e.g., Peter \& Valkenburg, 2006; Peter \& Valkenburg, 2008), 12 months (e.g., Brown \& L'Engle, 2009; Rogalo \& Tyden, 2003; Nelson et al., 2014; Svedin et al., 2011; Sinkovic et al., 2013) or even 12 - 24 months (e.g., Lo et al., 1999; Lo \& Wei, 2005). The current study addressed this methodological gap by measuring the impact of sexually explicit media use within three month period; a more realistic period within which participants will report their behavior outcomes more accurately.

Research in the field of sexual risk-taking is ongoing and far from being conclusive. Even with experimental designs (e.g., Jonas et al., 2014), it is clear that no findings are strong enough to draw conclusions regarding causality. It is clear from the studies that establishing a correlation between pornography consumption and sexual risk behavior would be a great step towards dealing with sexual risk behavior among adolescents and young adults (Rosser et al., 2012). Up to this point, the studies reviewed largely show a significant relationship between SEM use and sexual risk-taking. However, the association SEM use and sexual risk-taking is not consistent across board. Further, the literature also reflects a gap in investigating SEM use and sexual risktaking based on specific age bracket (i.e., 18 - 25 years). The current study addressed this gap by focusing on SEM use and sexual risk-taking among participants aged 18 - 25 years.

Based on Bandura's social learning theory that proposes reenactment of an observed action by an observer (Bandura, 1977), it was hypothesized that respondents who are highly exposed to SEM would report higher sexual risk-taking than those who are less exposed. In 


\section{PORN CONSUMPTION AND SEXUAL RISK-TAKING}

addition, based on the findings of prior studies that reported clear gender differences in SEM use, (e.g., Morgan, 2011) it was also predicted that males would report higher levels of SEM use than the females. Finally, it was predicted that males would report higher levels of SEM use as well as sexual risk-taking than the females. Finally, it was predicted that gender would moderate the association between SEM use and sexual risk-taking. The males who report higher levels of SEM use would also report higher levels of sexual risk-taking than the males who report lower levels of SEM use. Males reporting higher levels of SME use would also report higher sexual risk-taking than the females who report both high levels and low levels of SEM use. 


\section{Chapter III}

\section{Method}

\section{Participants}

Participants for the current study were recruited through Mechanical Turk on Amazon.com. A total of 146 participants responded to the online call for the survey. Sample sizes for related studies previously conducted have ranged between 227 (Wilkerson et al., 2012) to 1,228 participants (O’Hara et al., 2012).

Demographic characteristics. The mean age for participants was 22.89 ( $S D=1.94$; range $=18-27$ years $)$. Majority of the respondents were males $(54.9 \%)$. The females constituted 45.1\%. The sample was predominantly White/European American (74.6\%). Other races were Asian /Asian American (9.7\%), Black/African American (6.7\%), Native American (0.7\%) and other/multiethnic $(8.2 \%)$. The majority of the respondents $(37.7 \%)$ were single, $25.3 \%$ were in serious relationship but living apart, $17.8 \%$ in serious relationship and living together. Only $11 \%$ reported being married and even smaller percentage $(0.7 \%)$ reported being divorced.

In addition, the majority of the respondents $(40.1 \%)$ reported having attained some college education; another $36.5 \%$ reported having completed a four-year college degree, $10.9 \%$ had attained a two-year college degree and eight percent had attained high school level of education. A few of the participants (3.6\%) also reported having attained a Masters' degree. At the time of the survey, the majority of the respondents $(54.4 \%)$ were not enrolled in any college. The remaining $45.6 \%$ were enrolled in some college or university. The majority of those who were enrolled in some college of university (58.1\%) were attending a four-year university or college, $17.7 \%$ were attending a two-year junior college, or community college, $16.1 \%$ were 


\section{PORN CONSUMPTION AND SEXUAL RISK-TAKING}

enrolled in a four-year private university, $4.8 \%$ were attending other type of colleges or universities and 3.2\% were attending technical or vocational training college. In addition, the majority of the respondents $(61 \%)$ were living away from their parents (i.e. in an apartment or house, with roommates, partners or alone), $29.4 \%$ were living at home with their parents, $8.1 \%$ were living in the university/college dormitory, $0.7 \%$ living in Greek houses or other houses affiliated with a social organization/club or the remaining $0.7 \%$ were living somewhere else, $2.1 \%$ did not wish to answer the question and another $4.8 \%$ of the respondents skipped the question.

\section{Procedure}

The study was conducted through a web-based survey in which participants were recruited online through Amazon.com's Mechanical Turk. This is a survey system regulated by Amazon.com whereby potential participants register online and participate in different research surveys. As a participation incentive, the participants received US\$1 through Mechanical Turk for the completion of the survey.

\section{Instrumentation}

Three key outcome variables were examined. The variables were high risk sexual behavior (e.g., engaging in paid sex, sexual intercourse with a stranger or a prostitute, engaging in anal sex, and engaging in sex under the influence of drugs or alcohol), multiple sexual partners (number of lifetime sexual partners) and frequency of condom use within the previous 12 months (see Appendices A, B, and C). In addition to these, sexually explicit media use which is the independent variable for the current study was also examined (see Appendix D).

Sexually explicit media use. To measure the frequency of participant's intentional exposure to SEM, a four-item scale was used ("How often have you intentionally looked at (a) 


\section{PORN CONSUMPTION AND SEXUAL RISK-TAKING}

pictures with clearly exposed genitals, (b) movies with clearly exposed genitals, (c) pictures in which people were having sex, and (d) movies in which people were having sex"). The participants' responses were measured on seven-point scale that ranged from 1 (never) to 7 (several times a day) (see Appendix B) (Peter \& Valkenburg, 2008). In prior study, this measure had Cronbach's $\alpha$ of .95 which shows a high level of internal consistency. Similarly, the current study also had Cronbach's $\alpha$ of .93 which is a high reliability.

Multiple sexual partners. Lifetime sexual partners was assessed using a single openended item. The respondents were asked to indicate the actual number of people he/she had ever had sex with in their lifetime ("With how many people have you ever had sexual intercourse in your lifetime?") (see Appendix C).

Condom use. The frequency of condom use within the previous 12 months was assessed using a single item ("Thinking of all the times you have had sexual intercourse during the past 12 months, about what proportion of the time have you or a partner of yours used a condom?"). The responses to this item were measured on a five-point scale that ranged from 1 (none of the time) to 5 (all of the time).

High risk sexual behavior. A set of six items were used to assess high risk sexual behavior (Cooper et al., 1998). The participants were asked how often they had ever engaged in these behaviors, for example "Had sexual intercourse with a stranger or a prostitute". The participants' responses were measured on a six-point response scale that ranged from 1 (I have never engaged in this practice) to 6 (I engaged in the last month) (see Appendix D). A scale score was computed by averaging across the items. In their original article, Cooper et al. (1998) did not provide a Cronbach's alpha for this measure, but that study provided evidence of the measure's validity, in that high levels of high risk sexual behaviors were associated positively 


\section{PORN CONSUMPTION AND SEXUAL RISK-TAKING}

with engaging in sex to cope with negative emotions or enhance self-worth and negatively with engaging in sex to enhance intimacy. This measure in the current study has Cronbach's $\alpha$ of .59 which is close to an adequate level of reliability.

\section{Analysis Plan}

Hypothesis 1 was that there would be a positive correlation between exposure to sexually explicit media content and sexual risk behavior. Respondents highly exposed to sexually explicit media would show higher sexual risk-taking than those who are less exposed. This hypothesis was tested through a bivariate correlation. The outcome variables tested were, sexual risk behavior (i.e., multiple sexual partners, condom use, and high risk sexual behavior).

In hypothesis 2 it was predicted that males would show higher levels of SEM use than the females as well as higher levels of sexual risk taking than the females. This hypothesis was tested through an independent samples $t$ test. The first $t$ test was done with the participant's sex as the independent variable and SEM use as the dependent variable. The second $t$ test was done with participant's sex as an independent variable and each of the dependent variables (i.e., multiple sexual partners, condom use, and high risk sexual behavior) tested separately. In each case the mean scores of both sexes (i.e., males and females) were compared.

Hypothesis 3 was that the males who report higher levels of SEM use would also report higher levels of sexual risk-taking than the males who report lower levels of SEM use. Males reporting higher levels of SME use would also report higher sexual risk-taking than the females who report both high levels and low levels of SEM use. This hypothesis was tested through hierarchical regressions with main effects on step one and interaction effects added on the second step of analysis. In the second step, SEM use was mean-centered in order to compute the interaction between a person's SEM use and their sex (i.e., moderator variable). SEM use was 


\section{PORN CONSUMPTION AND SEXUAL RISK-TAKING}

then tested as a predictor of the dependent variable under study. Finally, the interaction between SEM use and the person's sex as a predictor of the dependent variable under study was tested. This analysis is based on Baron and Kenny (1986) framework for testing moderation. The framework also views a moderator as a variable influencing either the strength or direction of the association between independent and dependent variables. In the current study, it was

hypothesized that the relation between a person's SEM use and their sexual risk behavior would change based on their sex. 


\section{Chapter IV}

\section{Results}

\section{Preliminary Analyses}

Frequencies of variables of interest in the current study are presented in Table 1.

\section{Hypothesis 1: Sexually Explicit Media use and Sexual Risk-Taking}

The first hypothesis was that adolescents and emerging adults who are highly exposed to sexually explicit media would show higher sexual risk-taking than those who are less exposed. This hypothesis was tested by examining the bivariate correlations between sexually explicit media use and sexual risk-taking. The correlation between sexually explicit media use and multiple sexual partners was not significant, $r(116)=.07, p=.48$. A participant's number of sexual partners was not significantly associated with their sexually explicit media use. The correlation between sexually explicit media use and condom use was also not significant, $r(99)=$ $.18, p=.08$. This indicates that a participant's consistency of condom use was not significantly associated with their sexually explicit media use. However, this was a trend-level positive relation between sexually explicit media use and condom use, perhaps indicating that high levels of sexually explicit media use corresponded to high levels of condom use. The correlation between sexually explicit media use and high risk sexual behavior was also not significant, $r(122)=.14, p=.13$. This indicates that a participant's engagement in high risk sexual behavior was not significantly associated with their sexually explicit media use.

The findings of the study therefore revealed no significant correlation between a participant's consumption of pornography and their engagement in the different forms of sexual risk-taking. This indicates that there was no significant linear relationship between sexually explicit media use and sexual risk behavior. 


\section{PORN CONSUMPTION AND SEXUAL RISK-TAKING}

\section{Hypothesis 2: Differences in Levels of Sexually Explicit Media use Based on a Person's Sex}

The second hypothesis was that males would report higher levels of sexually explicit media use and of sexual risk-taking behaviors than the females. This hypothesis was tested in four $t$-tests with the participant's gender as the independent variable and sexually explicit media use and sexual risk-taking behaviors as the dependent variables.

Sexually explicit media use. An independent samples $t$ test comparing the mean scores of the male and the female participants revealed a significant difference between the means of the two groups in terms of sexually explicit media use, $t(121)=-6.00, p=.01$. Males' mean level of sexually explicit media use $(M=3.83, S D=1.72)$ was higher than females' mean level of sexually explicit media use $(M=2.13, S D=1.29)$.

Multiple sexual partners. An independent samples $t$ test comparing the mean scores of the males and the females in terms of multiple sexual partners did not show any significant difference between the two groups, $t(129)=.607, p=.82$. The mean for males $(M=5.07, S D=$ 6.42) was not significantly different from the mean for the females $(M=5.75, S D=6.07)$.

Condom use. An independent samples $t$ test comparing the mean scores of the males and the females in terms of condom use did not show any significant difference between the two groups, $t(114)=-1.14, p=.72$. The mean for the males $(M=3.07, S D=1.71)$ was not significantly different from the mean for the females $(M=2.70, S D=1.69)$.

High risk sexual behavior. An independent samples $t$ test comparing the mean scores of the male and the female participants revealed a significant difference between the means of the two groups in terms of high risk sexual behavior, $t(118)=-2.26 p=.03$. Males' mean level of high risk sexual behavior $(M=1.97, S D=1.28)$ was higher than females' mean level of high risk sexual behavior $(M=1.53, S D=.76)$. 
PORN CONSUMPTION AND SEXUAL RISK-TAKING

\section{Hypothesis 3: Gender as a Moderator Between Sexually Explicit Media Use and Sexual}

\section{Risk-Taking}

The third hypothesis was that the males who report higher levels of SEM use would also report higher levels of sexual risk-taking than the males who report lower levels of SEM use. Males reporting higher levels of SME use would also report higher sexual risk-taking than the females who report both high levels and low levels of SEM use. Hierarchical regression was used with main effects of a person's sex and sexually explicit media use on the first step and interaction added on second step. All interaction terms were calculated using mean centered variables (see Table 2).

Multiple sexual partners. The regression equation was not significant for multiple sexual partners in step one, $F(3,111)=1.15, p=.32, R^{2}=.02$. There was no significant association between a person's sex and their number of sexual partners. Further, there was also significant association between a person's SEM use and the number of their sexual partners. The second step did not explain any additional variance in their number of sexual partners, $\Delta F(3,110)=$ $1.69, p=.10, R^{2}=.04, \Delta R^{2}=.02$. However, SEM use was a significant predictor of a person's number of sexual partners such that high levels of SEM use was significantly associated with high number of sexual partners. Finally, the interaction between SEM use and a person's sex was not a significant predictor of their number of sexual partners.

Condom use. The regression equation was not significant for condom use in the first step, $F(2,93)=2.11, p=.33, R^{2}=.04$. There was no significant association between a person's sex and the consistency of their condom use. Further, there was also no significant association between SEM use and person's consistency of condom use. The second step did not explain any additional variance in the consistency of their condom use, $\Delta F(3,93)=1.41, p=.39, R^{2}=.04$, 


\section{PORN CONSUMPTION AND SEXUAL RISK-TAKING}

$\Delta R^{2}=.00$. Further, a person's SEM use was not a significant predictor of the consistency of their condom use. Finally, the interaction between SEM use and a person's sex was not a significant predictor of the consistency of their condom use.

High risk sexual behavior. The regression equation was not significant for high risk sexual behavior in step one, $F(2,117)=1.52, p=.22, R^{2}=.03$. There was no significant association between a person's sex and their engagement in high risk sexual behavior. Although the second step did not explain any additional variance in their engagement in high risk sexual behavior, $\Delta F(3,116)=1.52, p=.31, R^{2}=.04, \Delta R^{2}=.01$, SEM use was a significant predictor of a person's engagement in high risk sexual behavior. High level of SEM use was significantly associated with high levels of high risk sexual behavior. Finally, the interaction between SEM use and a person's sex was not a significant predictor of a person's engagement in high risk sexual behavior. 


\section{PORN CONSUMPTION AND SEXUAL RISK-TAKING}

\section{Chapter V}

\section{Discussion}

The purpose of the current study was to examine the relationship between sexually explicit media use and sexual risk behavior among adolescents and emerging adults aged $18-25$

years. This is a critical stage for sexual risk-taking which has not been adequately investigated by prior studies. It was hypothesized that teens and young adults who use sexually explicit media would show more sexual risk-taking. In addition, it was also predicted that males would report higher levels of sexually explicit media use than the females and that a person's sex would also moderate the link between their sexually explicit media use and their sexual risk-taking. The hypotheses of this study were partially supported in statistical analyses of data generated online from 146 respondents aged $18-25$ years. The findings did not show any significant associations between sexually explicit media use and sexual risk-taking. However, when all key constructs under study were examined concurrently in hierarchical regression analysis, sexually explicit media use significantly predicted a person's number of sexual partners and their engagement in high risk sexual behavior. The following is a discussion of the results for each of the study hypothesis.

\section{Overview of Findings}

Hypothesis 1: Sexually explicit media use and sexual risk-taking. Given that previous studies have empirically established a significant relationship between SEM use and different forms of sexual risk-taking, like multiple sexual partners (e.g., Morgan, 2011; O’Hara et al, 2012; Wright \& Randall, 2012), inconsistent condom use (e.g., Hagerty \& Matmor, 2012; Nelson et al., 2014; Wingood et al., 2001) and high risk sexual behavior (e.g., Svedi et al., 2011; Sinkovic et al., 2013), it was hypothesized that high levels of SEM use would be positively 


\section{PORN CONSUMPTION AND SEXUAL RISK-TAKING}

correlated with sexual risk-taking. The results revealed no significant correlations between participants' SEM use and engagement in sexual risk-taking. However, among the sexual risktaking variables (i.e., multiple sexual partners, inconsistent condom use and high risk sexual behavior), there was a trend-level positive relation between sexually explicit media use and condom use. The trend-level finding of the current study indicates that high SEM use might have some links with high frequency of condom use. This finding needs to be tested further in future studies especially with larger samples.

Further, the findings of the current study are a reflection of inconsistent findings in the existing literature. For example, Wright and Randall (2012) in their study of adult males (age 18 - 87 years) found a significant link between SEM use and multiple sexual partners but no such association was found with condom use. In addition, Luder and colleagues (2011) found a significant negative association between sexually explicit media use and condom use among males but no such significant association was found for the females. In sum, the findings for the current study provides additional evidence of the inconsistency in regard to the association between SEM use and sexual risk-taking. There is seems to be no direct or consistent correlation between SEM use and sexual risk-taking both in the current study and prior studies.

\section{Hypothesis 2: Gender differences in levels of SEM use and sexual risk-taking. In}

regard to hypothesis 2, it was predicted that there would be gender differences in levels of SEM use and well as sexual risk-taking. It was predicted that males would report higher levels of SEM use and higher levels of sexual risk-taking than the females. Consistent with the existing literature on sex differences in SEM use between males and females (e.g., Brown \& L'Engle, 2009; Morgan, 2011; Lo \& Wei, 2005), males reported significantly higher levels of SEM use than the females. In terms of sexual risk-taking, males and females were not significantly 


\section{PORN CONSUMPTION AND SEXUAL RISK-TAKING}

different in their condom use as well as number of sexual partners. However, there was a significant gender difference in high risk sexual behavior with males reporting higher levels of high risk sexual behavior than the females. It must be noted that there is a gap in the existing literature in terms analyzing the gender differences in sexual risk-taking. Prior have analyzed the gender differences in SEM use with males consistently reporting higher levels of SEM use than the females. The low levels of SEM use reported by the females might just be because the SEM is not widely used by the females or the females' desire to respond in a socially desirable way. Empirical studies have found that males score higher in sexual risk-taking than the females (Gullet \& Lyons, 2005). Based on this evidence, it might be that more males are driven to take sexual risks hence males reporting higher levels high risk sexual behavior than the females.

In sum, the findings of the current study provide additional support to those of prior studies as regards gender differences in SEM use. Future studies should examine what lies at the bottom of this gender difference. Specifically, the question of socially-desirable response versus objective response to questions related to SEM use should be explored. Future studies need to investigate whether the need for socially-desirable response might be contributing to the females underreporting of SEM use.

\section{Hypothesis 3: Person's sex as a moderator between SEM use and sexual risk-taking.}

In the third hypothesis, it was predicted that the males who report higher levels of SEM use would also report higher levels of sexual risk-taking than the males who report lower levels of SEM use. Males reporting higher levels of SME use would also report higher sexual risk-taking than the females who report both high levels and low levels of SEM use.

Regression analyses revealed that sexually explicit media use was a significant predictor of a person's number of sexual partners as well as their engagement in high risk sexual behavior. 


\section{PORN CONSUMPTION AND SEXUAL RISK-TAKING}

However, sexually explicit media use was not a significant predictor of a person's condom use. In addition, the interaction between sexually explicit media use and a person's sex was not a significant predictor of their number of sexual partners, their condom use and their engagement in high risk sexual behavior. This finding does not therefore support the hypothesis that had predicted that a person's sex would moderate the influence that sexually explicit media use had on their behavior. High levels of sexually explicit media use has been associated with multiple sexual partners (e.g., Morgan, 2011; Wright \& Randall, 2012). Some have also found an association between sexually explicit media use and multiple sexual partners. Although the findings of the current study does not support the hypothesis, it is consistent with those of the prior studies that have found an association between sexually explicit media use and sexual risktaking (e.g., Morgan, 2011; Wright \& Randall, 2012). The findings of the current study make a significant contribution especially given that there are sex differences in the levels of sexually explicit media use between males and females. In spite of this difference and based on the findings of the current study it is not possible to significantly predict if a person who consumes SEM is likely to engage in sexual risk-taking based on their sex.

Overall, the findings show that of all the constructs considered in this research, sexually explicit media use had an influence on a person's number of sexual partners, and their high sexual behavior. Although regression equation for condom use wasn't significant, the trend-level positive relation between sexually explicit media use and condom use is a finding that future research should explore.

\section{Study Contributions}

The current study is positioned to extend the existing literature in several ways. First, this study focused on participants aged $18-25$ years, an age group not widely investigated in the 


\section{PORN CONSUMPTION AND SEXUAL RISK-TAKING}

prior studies. Second, the study examined a combination of three forms of sexual risk-taking (i.e., multiple sexual partners, inconsistent condom use and high risk sexual behavior) and their association with sexually explicit media use. Third, this study carried out an analysis to compare the gender differences in sexual risk-taking, not just in SEM use as has been done by most prior studies.

Finally, the current study calls in question the role that a person's sex plays in the influence that sexually explicit media has on sexual risk-taking. Regression analysis revealed that among the sexual risk-taking variables under investigation, SEM use was only a significant predictor of a person's number of sexual partners as well as their engagement in high risk sexual behavior. This inconsistency in findings might be indicating that there could be other factors or variables (e.g., a person's temperament) that are influencing the link between SEM use and sexual risk-taking. While the role of gender in sexually explicit media use has been cited in prior studies (e.g., Morgan, 2011; O'Hara et al., 2012), few studies have explored the moderating role that gender plays in sexually explicit media use. Future studies should investigate gender role further especially using bigger sample size and a more ethnically diverse population.

\section{Study Limitations and Future Directions}

Despite its contribution to the existing body of knowledge, the current study has some noteworthy limitations. In addition to the variables that were analyzed (i.e., SEM use, multiple sexual partners, condom use and high risk sexual behavior), the current study also measured the length of viewing session as a way of gauging the intensity of SEM use. However, its results were not analyzed because the response rate was too low. Prior studies have examined SEM use in terms of how long the participants spent in each viewing session (e.g., Stein et al., 2012). It might be that sexual risk behavior outcome is determined by not just exposure to SEM but also 


\section{PORN CONSUMPTION AND SEXUAL RISK-TAKING}

the intensity of such exposure. Future research should consider reporting the length of viewing sessions to delineate the different levels of SEM use.

Processes at the root of gender differences in sexual risk-taking. In addition to establishing the differences between males and females in levels of SME use the current study also examined the gender differences in levels of sexual risk-taking among males and females who have been exposed to SME. Indeed prior studies report that SME use does not impact the males and the females uniformly. Males report greater impact in terms of sexual risk-taking than the females (O'Hara et al., 2012). Based on the findings of the current study, a person's sexual risk-taking could not be predicted based on their sex. Future studies should examine what lies at the root of these gender differences. In addition, future studies should also identify the various categories of pornography that are popularly consumed. Some prior studies have reported sexual risk behavior which were directly linked to the type of pornographic content consumed. For example in Traeen et al. (2015) study, participants who were exposed to scenes depicting unprotected anal intercourse were more likely to report infrequent condom use than those who were exposed to scenes depicting protected intercourse. (e.g., Nelson et al., 2014). Just as Rosser et al. (2012) pointed out, it may be that sexual risk behaviors vary across sexually explicit media users based on sexual media content they consume. Future researchers should adopt a comparatively detailed measures to gather data on the type of sexually explicit media consumed and to link them with an individual's sexual risk behaviors.

Diverse sample/larger sample size. In comparison to prior studies, the current study used a relatively small sample. Because of this, statistical analyses had low power which might have increased the risk of type II error. In addition, the current study was also predominantly White/European American. Future research should consider examining not just larger sample 


\section{PORN CONSUMPTION AND SEXUAL RISK-TAKING}

sizes but also more ethnically diverse sample to help test interaction effects of sexual risk-taking based on ethnicity. This is because most of the studies previously done were predominantly European American. This lack of ethnic balance might lower generalizability of the findings across different ethnic groups (e.g., Brown \& L'Engle, 2009; Nelson et al., 2014; O’Hara et al., 2012).

Participants' current place of residence. The demographics report showed that $29.4 \%$ of the respondents were staying at home with their parents. This has clear implications on the findings especially given that young people who stay at home with parents might not have the privacy or freedom they need to either use sexually explicit media or be engaged in sexual risk taking. Prior studies have revealed that parental monitoring has a significant impact on adolescent's sexual risk behavior. Teens who are closely monitored are likely report lower sexual risk-taking (i.e., one sexual partner, consistent condom use) than those who are not monitored by parents (Huebner \& Howell, 2003). Future studies need to take the participant's place of residence into account in order determine if parental control is acting as a third variable influencing the participant's engagement in sexual risk-taking.

\section{Conclusions}

Understanding the impact that sexually explicit media use has on sexual behavior especially during early adulthood is matter of health significance. This investigation contributed to the existing literature by focusing on $18-25$ years, an age group which has not been sufficiently investigated independently by prior studies. This age group is especially crucial given that it constitutes $50 \%$ (20 million) of the population currently facing the challenges of new cases of sexually transmitted infections recorded annually (CDC, 2016).

The current study also raised two questions that future studies need to pay close attention 


\section{PORN CONSUMPTION AND SEXUAL RISK-TAKING}

to. Considered in the light of Albert Bandura's theoretical model of observational learning (Bandura, 1977), the findings of the current study makes it clear that the link between observation and modelling of behavior is not as direct as assumed. In the current study, there were no significant association between SEM use and sexual risk-taking. This finding is inconsistent with Bandura's observational learning framework that views human behavior to be largely influenced by what is observed in the environment (Bandura, 1977). The findings therefore points to a conclusion that the influence that the environment has on a person's behavior might be moderated by other factors (e.g., a person's temperamental disposition, religious beliefs, etc.). For example, people who have a temperamental disposition of sensation seeking might have an inclination towards sexual risk-taking even in the absence of SEM use. Indeed sensation seeking, as a temperamental disposition has been found to be a significant factor behind sexual risk behavior for males and females (Gullette \& Lyons, 2005). Further, adherence to religious tradition has been found to act a protective factor against sexual risk behavior among teenagers. Adolescents who report high levels of religiosity are less likely to initiate sex or engage in sexual risk behaviors (Zaleski \& Schiaffino, 2000).

Second, in the current study, males reported higher levels of SEM use than the females. However, it was not possible in the current study to establish if SEM use had greater impact on the males more than the females. Similarly, males also reported higher levels of high risk sexual behavior than the females. This finding could be linked to prior studies in which males scored higher than the females at risk taking behavior (Gullette \& Lyons, 2005).

Third, the findings of this study, suggests that SEM use indeed has some influence on a person's sexual risk-taking specifically the number of their sexual partners and their engagement in high risk sexual behavior. Prior studies have however, not yet established the direction of this 


\section{PORN CONSUMPTION AND SEXUAL RISK-TAKING}

influence. It might be possible that people who are engaging in sexual risk-taking seek pornography that is in line with their sexual behavior, which means sexual risk behavior might influence SEM use just like SEM use could influence sexual risk behavior. This bidirectional relationship between SEM use and sexual risk-taking has not been sufficiently covered in the literature. Only one study was reviewed on bidirectional relationship in the current study (i.e., Bleakley et al., 2008). In their study, Bleakley and colleagues (2008) found that sexual risktaking predicted SEM use and SEM use in turn predicted sexual risk-taking. Exploring this bidirectional association would help establish the direction of influence between SEM use and sexual risk-taking.

Further, more studies should also explore the function that SEM serves for its consumers as well as the motives that drives them to use SEM. Prior studies have found that majority of SEM users visit pornographic online sites to distract themselves. A considerable number of SEM users $(35 \%)$ reported that they use SEM to educate themselves on sexual techniques (Cooper, Morahan-Martin, Mathy \& Maheu, 2002). Finding out what drives people to seek SEM might help explain partly the inconsistency in the findings as regards SEM use and sexual risk-taking. Overall, the findings of the study suggests that SEM use indeed has some level of influence on a person's sexual risk-taking. However, based on the findings of the current study and those of prior studies, this influence is not consistent. This is a possible indicator that the link between SEM use and sexual risk-taking might be influenced by other variables. 


\section{APPENDIX A}

\section{Background/ Demographic information}

These questions are about your background characteristics. Remember, there are no right or wrong answers. So please answer these questions as honestly as possible. Also, remember that you are free to skip any items you do not wish to answer for any reason.

What is your sex? $\square$ Male $\quad \square$ Female $\quad \square$ Do not wish to answer

What is your age in years? Please leave the box blank if you do not wish to answer this question

Where do you currently live?

At home with parents

University / College Dormitory

Greek house or other house affiliated with a social organization /club

Apartment or house (with roommates, partner, alone or other

Somewhere else (please specify)

Do not wish to answer

Do you presently live in the United States? $\square$ Yes $\quad \square$ No

In which do you currently reside?

What is your relationship/marital status?

$\square$ Single, never married

In a serious romantic relationship - not living together 


\section{PORN CONSUMPTION AND SEXUAL RISK-TAKING}

$\square$ In a serious romantic relationship - living together

$\square$ Married

$\square$ Separated

Divorced

Other (Please specify)

Do not wish to answer

Do you consider yourself to be Hispanic or Latino?

$\square$ Yes

$\square$ No

$\square$ Do not wish to answer

To what racial group do you belong? Please check all that apply

$\square$ Native American / Indian

$\square$ Black / African American

$\square$ White /Caucasian

Asian /Asian American

$\square$ Pacific Islander

Other (Please specify)

Do not wish to answer

What is the highest level of education you have completed?

Less than High School

$\square$ High School /GED 


\section{PORN CONSUMPTION AND SEXUAL RISK-TAKING}

$\square$ Some College

$\square$ 2-year College Degree

$\square$ 4-year College Degree

$\square$ Masters Degree

Doctoral Degree

Professional Degree (JD, MD)

Are you currently enrolled in college or university?

$\square$ Yes

$\square$ No

Do not wish to answer

You indicated that you are currently enrolled in college or university or will be enrolled this Fall What is your current year in school (or will be your current year in school, as of this Fall)?

$\square$ First year (“freshman”)

Second year ("sophomore")

$\square$ Third year (“junior”)

Fourth year ("senior")

Other (please specify)

Do not wish to answer

Are you a first-generation college student?

$\square$ Yes --- Neither of my parents went to college / university

$\square$ No --- One of both of my parents went to college /university 


\section{PORN CONSUMPTION AND SEXUAL RISK-TAKING}

Do not wish to answer

What is your "major?" If you do not wish to answer this question, please leave this box blank.

What type of college or university do you attend?

Technical or vocational training college

$\square$ Two-year college, junior college, or community college

Four-year public university or college

Four-year private university or college

Other type of college or university (please explain)

Do not wish to answer

Please choose the description that best fits how you think about yourself.

$100 \%$ heterosexual (straight)

$\square$ Mostly heterosexual (straight), but somewhat attracted to people of your own sex

$\square$ Bisexual, that is, attracted to men and women equally

$\square$ Mostly homosexual (gay), but somewhat attracted to people of the opposite sex

$100 \%$ homosexual (gay)

Not sexually attracted to either males or females

Do not wish to answer 


\section{APPENDIX B}

\section{Frequency of intentional exposure to sexually explicit media}

Within the last 3 months how often have you intentionally looked at (a) pictures with clearly exposed genitals, (b) movies with clearly exposed genitals, (c) pictures in which people were having sex, and (d) movies in which people were having sex?

(1) Never

2 Less than once a month

(3) 1 - 3 times a month

(4) Once a week

5 Several times a week

6 Every day

(7) Several times a day

$\square$ Do not wish to answer 


\section{APPENDIX C}

\section{Number of sexual partners}

With how many people have you ever had sexual intercourse in your lifetime? (sexual intercourse' means anal, vaginal, or oral contact with a person of the opposite sex or same sex). Please enter the number below, or leave this box blank if you do not wish to answer this question.

\section{Condom use}

Thinking of all the times you have had sexual intercourse during the past 12 months, about what proportion of the time have you or a partner of yours used a condom?

(1) None of the time

(2) Some of the time

3 Half of the time

(4) Most of the time

5 All of the time

$\square$ Don’t know /Unsure

$\square$ Do not wish to answer 


\section{APPENDIX D}

\section{High risk sexual behavior}

Have you ever engaged in any of these practices? If yes, how recently did you last engage in this practice? The word 'sexual intercourse' means anal, vaginal, or oral contact with a person of the opposite sex or same sex

\begin{tabular}{|c|c|c|c|c|c|c|c|}
\hline & $\begin{array}{l}\text { No- I have } \\
\text { never } \\
\text { engaged } \\
\text { in this } \\
\text { practice }\end{array}$ & $\begin{array}{l}\text { Yes- } \\
\text { More } \\
\text { than one } \\
\text { year ago }\end{array}$ & $\begin{array}{l}\text { Yes, } 6- \\
12 \\
\text { months } \\
\text { ago }\end{array}$ & $\begin{array}{l}\text { Yes, } 3- \\
6 \text { months } \\
\text { ago }\end{array}$ & $\begin{array}{l}\text { Yes, } 1- \\
3 \text { months } \\
\text { ago }\end{array}$ & $\begin{array}{l}\text { Yes, in } \\
\text { the last } \\
\text { month }\end{array}$ & $\begin{array}{l}\text { Do not } \\
\text { wish to } \\
\text { answer }\end{array}$ \\
\hline $\begin{array}{l}\text { Had a "one night } \\
\text { stand" (i.e., had } \\
\text { sexual intercourse } \\
\text { on one and only } \\
\text { occasion }\end{array}$ & (1) & 2 & (3) & 4 & (5) & 6 & 7 \\
\hline $\begin{array}{l}\text { Had sexual } \\
\text { intercourse with a } \\
\text { stranger or a } \\
\text { prostitute }\end{array}$ & & & & & & & \\
\hline $\begin{array}{l}\text { Had anal } \\
\text { intercourse }\end{array}$ & & & & & & & \\
\hline $\begin{array}{l}\text { Had sexual } \\
\text { intercourse in } \\
\text { exchange for } \\
\text { drugs or money }\end{array}$ & & & & & & & \\
\hline $\begin{array}{l}\text { Had sexual } \\
\text { intercourse with } \\
\text { someone who has } \\
\text { had many sexual } \\
\text { partners, has used } \\
\text { IV drugs, or is } \\
\text { infected with } \\
\text { HIV/AIDS }\end{array}$ & & & & & & & \\
\hline $\begin{array}{l}\text { Had sexual } \\
\text { intercourse while } \\
\text { under the } \\
\text { influence of } \\
\text { alcohol or drugs }\end{array}$ & & & & & & & \\
\hline
\end{tabular}




\section{PORN CONSUMPTION AND SEXUAL RISK-TAKING}

\section{References}

Bandura, A. (2001). Social cognitive theory: An agentic perspective. Annual Review of Psychology, 52, 1-26.

Bandura, A. (1977). Social learning theory. Eaglewood Cliffs, NJ: Prentice-Hall.

Baron, M. R., \& Kenny, D. A. (1986). The moderator-mediator variable distinction in social psychological research: Conceptual, strategic, and statistical considerations. Journal and Personality and Social Psychology, 51, 1173 - 1182.

Bleakley, A., Hennessy, M., Fishbein, M., \& Jordan, M. (2008). It works both ways: The relationship between exposure to sexual content in the media and adolescent sexual behavior. Media Psychology, 11, 443-461.

Braun-Courville, D. K., \& Rojas, M. (2009). Exposure to sexually explicit websites and adolescent sexual attitudes and behaviors. Journal of Adolescent Health, 45, 156- 162.

Brown, J. D., \& L'Engle, K. L. (2009). X-Rated: Sexual attitude and behaviors associated with U.S. early adolescents' exposure to sexually explicit media. Communication Research, $36,129-151$.

Cavazos-Rehg, P. A., Krauss, M. J., Spitznagel, E. L., Schootman, M., Bucholz, K. K., Peipert, J. F., ... Beirut, J. L. (2009). Age of sexual debut among US adolescents. Contraception, 80, $158-162$.

Centers for Disease Control and Prevention. (2015). HIV infection, risk, prevention, and testing behaviors among persons who inject drugs - National HIV behavioral surveillance: Injection drug use, 20 U.S. cities, 2012. HIV Surveillance Special Report 11. Retrieved from http://www.cdc.gov/hiv/library/reports/surveillance/

Centers for Disease Control and Prevention. (2016). About teen pregnancy. Retrieved from http://www.cdc.gov/teenpregnancy/about/index.htm 


\section{PORN CONSUMPTION AND SEXUAL RISK-TAKING}

Chesson, H. W., Blandford, J. M., Gift, T. L., Tao, G., \& Irwin, K. L. (2004). The estimated direct medical cost of sexually transmitted diseases among American youth, 2000. Perspectives on Sexual and Reproductive Health, 36, 11-19.

Cooper, M. L., Shapiro, C. M., \& Powers, A. M. (1998). Motivations of sex and risky sexual behavior among adolescents and young adults: A functional perspective. Journal of Personality and Social Psychology, 75, 1528-1558

Cooper, A., Morahan-Martin, J., Mathy, R. M., \& Maheu, M. (2002). Towards an increased understanding of user demographics in online sexual activities. Journal of Sex \& Marital Therapy, 28, $105-129$

Darroch, E. J, Singh, S., \& Frost, J. J. (2001). Differences in teenage pregnancy rates among five developed countries: The roles of sexual activity and contraceptive use. Family Planning Perspectives, 33, 244-250.

File, T., \& Ryan, C. (2014). Computer and internet use in the United States: 2013. American Community Survey Reports, 28, 1 - 16.

Frieden, T. R., Jaffee, H. W., Cono, J., Richards, C. L., \& Iademarco, M. F. (2014). Youth risk behavior surveillance - United States, 2013. Morbidity and Mortality Weekly Report, 63(4), 1-168.

Hennessy, M., Bleakley, A., Fishbein, M., \& Jordan, A. (2009). Estimating the longitudinal association between adolescent sexual behavior and exposure to sexual media content. Journal of Sex Research, 46, 586-596.

Huebner, A. J., \& Howell, L. W. (2003). Examining the relationship between adolescent sexual risk-taking and perceptions of monitoring, communication, and parenting style. Journal of Adolescent Health, 33, $71-78$ 


\section{PORN CONSUMPTION AND SEXUAL RISK-TAKING}

Gottfried, A. J., Vaala, S. E., Bleakley, A., Hennessy, M., \& Jordan, A. (2011). Does the effect of exposure to TV sex on adolescent sexual behavior vary by genre? Communication Research, 20, 1-23.

Gullette, D. L. \& Lyons, M. A. (2005). Sexual sensation seeking, compulsivity and HIV risk behaviors in college students. Journal of Community Health Nursing, 22, 47 - 60

Jonas, K. K., Hawk, T. S., Vastenburg, D., \& Groot, P. (2014). Bareback pornography consumption and safe-sex intentions of men having sex with men. Archives of Sexual Behavior, 43, 745-753.

Kearney, M. S., \& Levine, P. B. (2012). Why is the teen birth rate in the United States so high and why does it matter? Journal of Economic Perspectives, 26, 141 - 163.

Lo, V., \& Wei, R. (2005). Exposure to internet pornography and Taiwanese adolescents' sexual attitudes and behavior. Journal of Broadcasting and Electronic Media, 49, 221-237.

Lo, V., Neilan, E., Sun, M., \& Chiang, S. (1999). Exposure of Taiwanese adolescents to pornographic media and its impact on sexual attitudes and behavior. Asian Journal of Communication, 9, 50-71.

Luder, M. T., Pittet, I., Berchtold, A., Akre, C., Michaud, P. A., \& Suris, C. J. (2011). Associations between online pornography and sexual behavior among adolescents: Myth or reality? Archives of Sexual Behavior, 40, 1027-1035.

Martin, J. A., Hamilton, B. E., Osterman, M. J. K., Curtin, S. C., \& Mathews, T. J. (2011). Births: Final Data for 2011 - United States, 2013. National Vital Statistics Reports, 62(1), 1 90.

Morgan, E. (2011). Associations between young adults' use of sexually explicit materials and their sexual preferences, behaviors and satisfaction. Journal of Sex Research, 48, 520 - 


\section{PORN CONSUMPTION AND SEXUAL RISK-TAKING}

530.

Nelson, K. M., Simoni, J. M., Morrison, D. M., George, W. H., Leickly, E., Lengua, L. J., \& Hawes, S. E. (2014). Sexually explicit online media and sexual risk among men who have sex with men in the United States. Archives of Sexual Behavior, 43, 833-843.

Nordin, E. H., Hanson, U., \& Tyden, T. (2005). Association between pornography consumption and sexual practices among adolescents in Sweden. International Journal of STD \& AIDS, 16, 102-107.

O’Hara, R. E., Gibbons, F. X., Gerrard, M., Li, Z., \& Sargent, J. D. (2012). Greater exposure to sexual content in popular movies predicts earlier sexual debut and increased sexual risk taking. Psychological Science, 23, 984-993.

Peter, J., \& Valkenburg, P. M. (2006). Adolescents' exposure to sexually explicit online material and recreational attitudes towards sex. Journal of Communication, 56, 639-660.

Peter, J., \& Valkenburg, P. M. (2008). Adolescents' exposure to sexually explicit internet material, sexual uncertainty, and attitudes towards uncommitted sexual exploration: Is there a link? Communication Research, 35, 579-601.

Peterson, J. L., Coates, T. J., Catania, J. A., Middleton, L., Hilliard, B., \& Hearst, N. (1992). High risk sexual behavior and condom use among gay and bisexual African American men. American Journal of Public Health, 82, 1490-1494.

Rogala, C., \& Tyden, T. (2003). Does pornography influence young women's sexual behavior? Women's Health Issues, 13, 39-43.

Rosser, B. R. S., Grey, J. A., Wilkerson, J. M., Iantaffi, A., Brady, S. S., Smolenski, D. J., \& Horvath, K. J. (2012). A commentary on the role of sexually explicit media (SEM) in the transmission and prevention of HIV among men who have sex with men (MSM). AIDS 


\section{PORN CONSUMPTION AND SEXUAL RISK-TAKING}

Behavior, 16, 1373-1381.

Rosser, B. R .S., Smolenski, D. J., Erickson, D., Iantaffi, A., Brady, S. S., Grey, J. A., . . Hald, G. M. (2013). The effects of gay sexually explicit media on HIV risk behavior of men who have sex with men. AIDS Behavior, 17, 1488-1498.

Sinkovic, M., Stulhofer, A., \& Bozic, J. (2013). Revisiting the association between pornography use and risky sexual behaviors: The role of early exposure to pornography and sexual sensation seeking. Journal of Sex Research, 50, 633-641.

Stein, D., Silvera, R., Hagerty, R., \& Marmor, M. (2012). Viewing pornography depicting unprotected anal intercourse: Are there implications for HIV prevention among men who have sex with men? Archives of Sex Behavior, 41, 411-419.

Svedin, G. C., Akerman, I., \& Priebe, G. (2011). Frequent users of pornography. A population based epidemiological study of Swedish male adolescents. Journal of Adolescence, 34, 779-788.

Træen, B., Noor, S.W., Hald, G. M., Rosser, B. R. S., Brady, S. S., Erickson, D., . . Galos, D. L. (2015). Examining the relationship between use of sexually explicit media and sexual risk behavior in a sample of men who have sex with men in Norway. Scandinavian Journal of Psychology, 56, 290-296.

Vanable, P. A., Buchbinder, S. P., Douglas, J. M., Judson, F. N., McKirnan, D. J., Bartholow, B. N., \& MacQueen, K. M. (2004). Alcohol use and high risk sexual behavior among men who have sex with men: The effects of consumption level and partner type. Health Psychology, 23, 525-532.

Wingood, G. M, DiClemente, R. J., Harrington, K., Davies, S., Hook, E.W., \& Oh, M. K. (2001). Exposure to x-rated movies and adolescents' sexual and contraceptive-related attitudes 


\section{PORN CONSUMPTION AND SEXUAL RISK-TAKING}

and behaviors. Pediatrics, 107, $1116-1119$.

Wilkerson, J. M., Iantaffi, A., Smolenski, D. J., Brady, S. S., Horvath, K. J., Grey, J. A., \& Rosser, B. R. (2012). The SEM risk behavior (SRB) model: A new conceptual model of how pornography influences the sexual intentions and HIV risk behavior of MSM. Sexual Relationship Therapy, 27, 217-230.

Wright, P. J., \& Randall, A. K. (2012). Internet pornography exposure and risky sexual behavior among adult males in the United States. Computers in Human Behavior, 28, 1410-1416.

Ybarra, M. L., \& Mitchell, K. J. (2005). Exposure to Internet pornography among children and adolescents: A national survey. Cyber Psychology and Behavior, 8, 473-486.

Zaleski, E. H., \& Schiaffino, M. K. (2000). Religiosity and sexual risk-taking behavior during the transition to college. Journal of Adolescence, 23, $223-227$. 
PORN CONSUMPTION AND SEXUAL RISK-TAKING

Table 1

Descriptive Statistics

\begin{tabular}{lcll}
\hline Variable & $N$ & $M(S D) / \%$ & Range \\
\hline Person's sex (Male) & 144 & $54.9 \%$ & $0-1$ \\
Sexually explicit media use & 123 & $3.04(1.74)$ & $1-7$ \\
Multiple sexual partners & 131 & $5.46(6.41)$ & $0-28$ \\
Condom use & 116 & $2.92(1.70)$ & $0-5$ \\
High risk sexual behavior & 141 & $1.59(.60)$ & $1-4.33$ \\
\hline
\end{tabular}




\section{PORN CONSUMPTION AND SEXUAL RISK-TAKING}

Table 2

Hierarchical Regressions Predicting Sexual Risk-Taking Outcomes

\begin{tabular}{|c|c|c|c|c|c|c|}
\hline & MSP & & Condo & & High $\mathrm{I}$ & xual Behavior \\
\hline \multirow[t]{2}{*}{ Predictor } & Step 1 & Step 2 & Step 1 & Step 2 & Step 1 & Step 2 \\
\hline & $\beta$ & $\beta$ & $\beta$ & $\beta$ & $\beta$ & $\beta$ \\
\hline Person's Sex & -.13 & -.19 & .12 & .11 & -.08 & -.11 \\
\hline SEM use & .15 & $.43 *$ & .12 & .16 & .18 & $.37^{*}$ \\
\hline Interaction & & -.30 & & -.05 & & -.21 \\
\hline$R^{2}$ & .02 & .04 & .04 & .04 & .03 & .04 \\
\hline
\end{tabular}

Note. ${ }^{*} p<.05$, SEM $=$ Sexually Explicit Media, MSP $=$ Multiple Sexual Partners 